Goto, H; Kawabata, K

Light driven asymmetric polymerization: an approach for tele-control reaction POLYMER CHEMISTRY (UK), 2(5), 1098-1106 (2011).

\title{
Light driven asymmetric polymerization: an approach for tele-contol reaction
}

Hiromasa Goto*, Kohsuke Kawabata

Institute of Materials Science, Graduate School of Pure and Applied Sciences,

University of Tsukuba, Tsukuba, Ibaraki, 305-8573 Japan.

E-mail: gotoh@ims.tsukuba.ac.jp; Fax: +81-298-53-4490; Tel: +81-298-53-5128

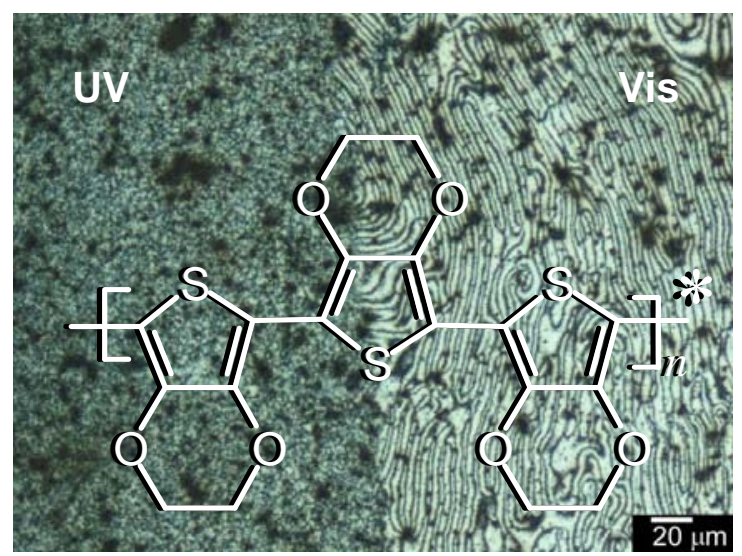

Light driven asymmetric polymerization: an approach for tele-command reaction

H. Goto*, K. Kawabata

Chiroptical activity tuning polymerization in liquid crystal (LC) electrolyte solution under irradiation of UV or Vis light was performed. 


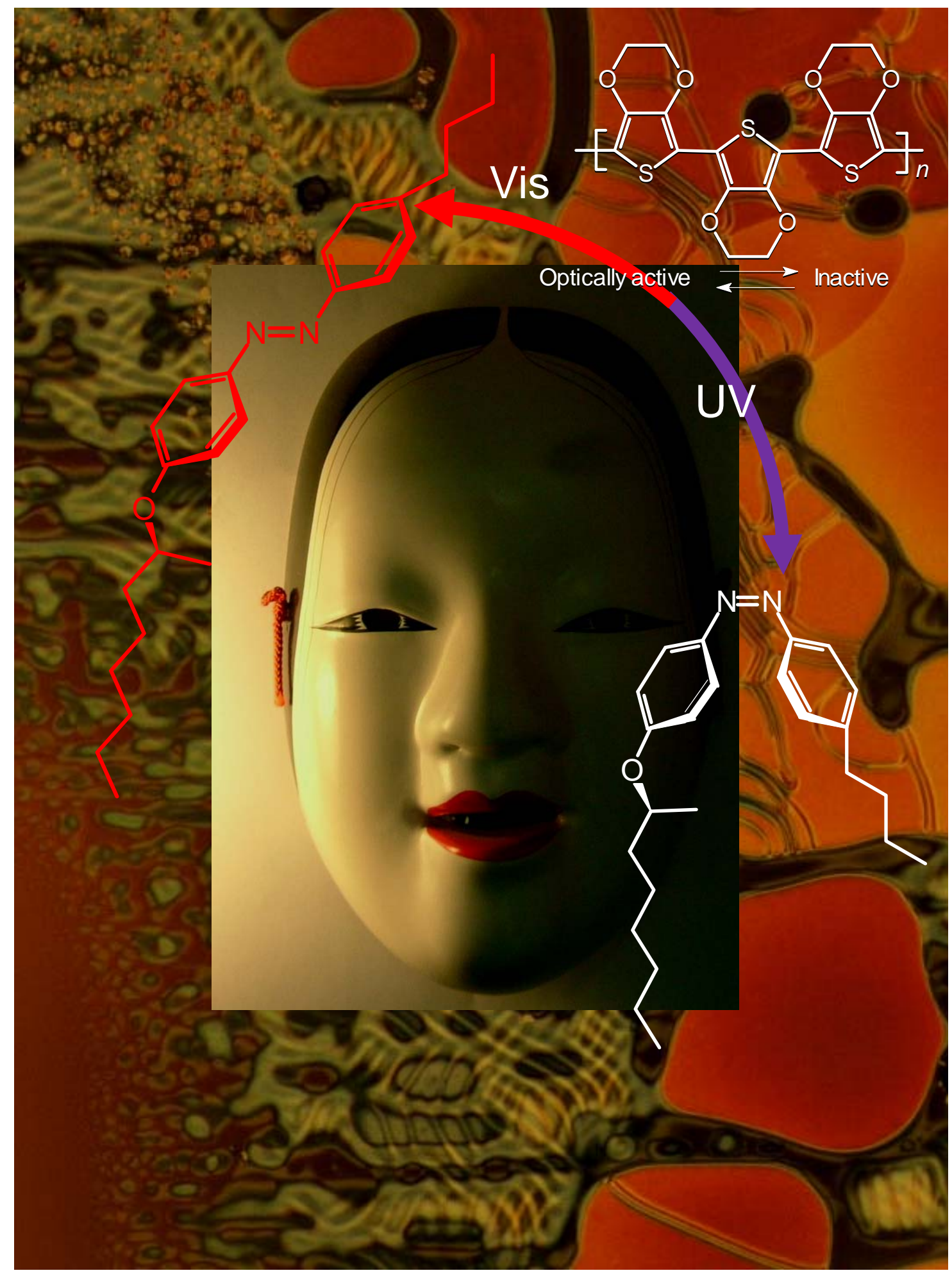

Electro-optically active $\pi$-conjugated polymers are prepared electrochemically in liquid crystal electrolyte solution displaying a photo-isomerization property. UV and Vis light irradiation allows tuning of chiroptical activity of resultant polymers. The background shows intermediate states of transition of cholesteric liquid crystal electrolyte solution to isotropic state accompanied by photo-isomerization from a trans to cis form of a photo-isomerization dopant. 
Goto, H; Kawabata, K

Light driven asymmetric polymerization: an approach for tele-control reaction POLYMER CHEMISTRY (UK), 2(5), 1098-1106 (2011).

\section{Abstract}

Chiroptical activity-tunable electro-polymerization is carried out in liquid crystal (LC) electrolyte solution under irradiation by UV or visible (Vis) light. The LC electrolyte prepared in this study undergoes photo-induced phase transition through trans-cis isomerization of azobenzene-based photo-isomerization dopant in the LC electrolyte solution. The trans-cis isomerization of the photo-isomerization dopant induced by UV light changes the structural chirality of the cholesteric LC electrolyte solution, which allows chiroptical activity tuning under the polymerization conditions. The results demonstrate realization of light-commandable asymmetric polymerization through change in a chiral environment for the electro-polymerization reaction. Note that the chiral polymer thus synthesized shows redox (electrochemical doping/dedoping)-driven change in chiroptical activity. This method can be used to induce light-driven asymmetric chemical reactions.

Keywords: chiral, cis-trans isomerization, cholesteric, photochromism, photo-induced phase transition, liquid crystal. 
Goto, H; Kawabata, K

Light driven asymmetric polymerization: an approach for tele-control reaction POLYMER CHEMISTRY (UK), 2(5), 1098-1106 (2011).

\section{Introduction}

Electrochemical polymerization is a useful method of preparing electroactive $\pi$-conjugated polymers. These polymers thus prepared have been studied for applications in electrochromic devices, ${ }^{1}$ transparent electrodes, and sensors. The product of the reaction is in the form of a film on the electrode surface. Polymer films synthesized by the electrochemical method in isotropic solution exhibit no linear dichroism or circular dichroism (CD). Electrochemical polymerization (electro-polymerization) in liquid crystal (LC) has been developed, ${ }^{2}$ and the resultant polymers thus prepared display fingerprint texture, ${ }^{3}$ Schlieren texture, ${ }^{3}$ fan-shaped texture, or ellipsoidal texture ${ }^{4}$ under scanning electron microscopy (SEM) and polarizing optical microscopy (POM). This method previously developed by the author provides polymers with redox-driven chiroptically active function. ${ }^{5}$ Furthermore, linearly polarized electrochromic effect was shown for the polymers with nematic, cholesteric, and smectic A (SmA) order prepared by electro-polymerization in LC under magnetic field. ${ }^{4}$

Azobenzene is a well-known photosensitive chromophore that undergoes photo-induced cis-trans reversible isomerization. Command surface systems to control 
Goto, H; Kawabata, K

Light driven asymmetric polymerization: an approach for tele-control reaction POLYMER CHEMISTRY (UK), 2(5), 1098-1106 (2011).

molecular alignment have been studied by using azobenzene. ${ }^{6}$ The photochromic properties due to mechanical change ${ }^{7}$ in molecular form can be applied for tuning of the reaction field.

Cholesteric LC is a twisted nematic phase of LC in which the directors are rotated progressively to form a helical structure. The helical aggregation of rod-like molecules in cholesteric LC results in periodicity, and the three-dimensional (3-D) molecular arrangement produces structural chirality.

Many living organisms possess cholesteric LC structures. The exoskeleton of insects with cholesteric order shows dazzling reflection of light. These are referred to as photonic insects. For example, the wings of golden beetles have multi-layer structure at the microscopic level. ${ }^{8}$ In particular, a jewel beetle cuticle consists of alternation of cholesteric layers and nematic layers of proteins. ${ }^{9}$ The polymer prepared in the present study shows rainbow-colored light reflection because the polymer forms a cholesteric LC-like structure.

The photo-induced phase transition can be applied for selective synthesis of optically active or inactive polymers or tuning of chiroptical activity by light. Photo-isomerizable molecules such as azobenzenes, spiropyranes, spiroxazine, ${ }^{10}$ spiroperimidine ${ }^{11}$ and diarylethenes ${ }^{12}$ can be useful as photo-induced phase transition 
Goto, H; Kawabata, K

Light driven asymmetric polymerization: an approach for tele-control reaction POLYMER CHEMISTRY (UK), 2(5), 1098-1106 (2011).

agents (photo-isomerization inducers) in LCs because the mechanical change in molecular order of LC can lead to phase transition of the entire LC system. Small amounts of photo-isomerizable molecules in an LC matrix, therefore, can control phase transitions in the entire LC system. This function is comparable to chiral dopant, which produces a cholesteric phase or chiral smectic phase (i.e., chiral smectic $\mathrm{C}, \mathrm{SmC}^{*}$ ) from a nematic or achiral smectic phase (i.e., SmC) by addition of small amounts of optically active molecules. Here, small amounts of a compound with a particular property change a physical property of the entire system.

Addition of small amounts of molecules to an appropriate matrix is referred to as doping, and the agent as dopant. In this study, $\pi$-conjugated polymers are electrochemically synthesized in a photo-isomerizable LC electrolyte solution. The $\pi$-conjugated system in polymers is a precursor of conducting polymers because an addition of small amount of electron acceptor or donor to $\pi$-conjugated polymers produces electrically conducting systems through the generation of polarons as charge carriers.

The impurities (additives) of electron acceptor or donor are typical dopants in electronics. However, this study employs three types of doping effects in several research directions: 1) construction of cholesteric LC with "chiral dopant" (LC 
Goto, H; Kawabata, K

Light driven asymmetric polymerization: an approach for tele-control reaction POLYMER CHEMISTRY (UK), 2(5), 1098-1106 (2011).

chemistry research); 2) construction of photo-isomerization systems with "photo-isomerization dopant" for a LC electrolyte solution (chemistry of photochromism); and 3) control of chiroptical activity for resultant redox-optically active polymers with electrochemical doping (oxidation) (“electro-dopant", electronics), as shown in Scheme S1, ESI†. In this study, an azobenzene derivative with chirality is employed as a chiral photo-isomerization dopant. The compound has two functions-chiral dopant and photo-isomerization dopant. Also, chiroptical activity-tuning by light-driven electro-polymerization is carried out by using a photo-sensitive chiral matrix LC electrolyte solution containing the chiral azobenzene.

The polymerization in cholesteric LC and tuning of chiroptical activity with light may be comparable to biological processes in the exoskeleton of photonic insects, as a form of artificial biomimetic technology.

\section{Experimental}

\section{Synthesis of photo-isomerization dopants}

An azobenzene derivative having chiral carbon in its terminal alkyl group, (S)-(+)-4-butyl-[4-(1-methyl-heptyloxy)-azobenzene], abbreviated as AZO*, was 
Goto, H; Kawabata, K

Light driven asymmetric polymerization: an approach for tele-control reaction POLYMER CHEMISTRY (UK), 2(5), 1098-1106 (2011).

synthesized for the preparation of the chiral photo-isomerization dopant (Scheme 1). 4-Butyl-4'-hydroxyazobenzene and (R)-(-)-octanol were coupled using diethylazodicarboxylate (DEAD) and triphenylphosphine (TPP) in tetrahydrofuran (THF) solution, according to the Mitsunobu reaction. The absolute configuration at the chiral center in the terminal alkyl group was inverted to $(S)$-configuration via the Mitsunobu inversion mechanism of the $\mathrm{S}_{\mathrm{N}} 2$ reaction. ${ }^{13}$ The chemical structure of AZO* was confirmed by heteronuclear multiple quantum coherence (HMQC) 2-D ${ }^{1} \mathrm{H}_{-}{ }^{13} \mathrm{C}$ correlation NMR spectroscopy (Fig. S1, ESI†). AZO* functions as a chiral dopant for the achiral nematic LC matrix for the formation of the cholesteric phase with structural chirality. The helical twisting power $(\beta)$ of the AZO* in 4-cyano-4'-hexyl biphenyl $(6 \mathrm{CB}$, matrix LC) is obtained as,

$$
\beta=1 / p c r,
$$

where $p, c$, and $r$, are helical pitch, molar concentration, and refractive index, respectively $(p=2 a \cdot \tan \theta$, where $a=$ Cano-line length, obtained with the Grandjean-Cano-wedge method. ${ }^{14}$ ). The $\beta$ value of AZO* is $0.49 \mu \mathrm{m}^{-1}$ at $21{ }^{\circ} \mathrm{C}$ as synthesized (before UV irradiation), obtained from the above equation. 
Goto, H; Kawabata, K

Light driven asymmetric polymerization: an approach for tele-control reaction POLYMER CHEMISTRY (UK), 2(5), 1098-1106 (2011).

\section{Synthesis of monomers}

In this study, two types of monomers were employed, $2,3,2^{\prime}, 3^{\prime}, 2^{\prime \prime}, 3-$ hexahydro-[5,5': $\left.7^{\prime}, 5^{\prime \prime}\right] \operatorname{ter}($ thieno[3,4-b][1,4]dioxine), abbreviated as terEDOT, and 2,7-di(2-furyl)fluorine (furan-fluorene-furan, abbreviated as FFLF) .

Synthetic routes for the monomers were outlined in Scheme 2. The terEDOT was prepared by the previously reported method. ${ }^{3}$ FFLF was synthesized according to the Migita-Kosugi-Stille coupling reaction. ${ }^{15}$ 2-(Tributylstannyl)furan and 2,7-dibromofluorene were coupled with the $\operatorname{Pd}(0)$ catalyst $\left[\mathrm{Pd}\left(\mathrm{PPh}_{3}\right)_{4}\right]$ in toluene solution to yield FFLF with $88 \%$ yield.

\section{Results and discussion}

\section{Photo-isomerization in chloroform solution}

Fig. 1 shows changes in optical absorption spectra for AZO* in chloroform solution during irradiation of UV or Vis light. The absorptions at $350 \mathrm{~nm}\left(\pi-\pi^{*}\right.$ transition) due to the trans form weakens upon irradiation of UV light, accompanied by a strengthening of the absorption band at $440 \mathrm{~nm}(\mathrm{n}-\pi *$ transition) due to the cis form. Subsequently, 
Goto, H; Kawabata, K

Light driven asymmetric polymerization: an approach for tele-control reaction POLYMER CHEMISTRY (UK), 2(5), 1098-1106 (2011).

irradiation with Vis light caused an increase in the intensity of the absorption band at $350 \mathrm{~nm}$, and a weakening of the band at $440 \mathrm{~nm}$. These results suggest that reversible trans-cis isomerization and photochromic behavior of the azobenzene moiety occur upon UV and Vis light irradiation.

\section{Photo-isomerization-driven change in optical texture}

Photo-induced phase transition of the LC with $\mathrm{AZO}^{*}$ was examined. The sample was sandwiched between thin glass slides (no spacer). The mixture containing AZO* $\left(\mathrm{AZO}^{*}=20 \mathrm{mg}, 6 \mathrm{CB}=0.3 \mathrm{~g}\right)$ showed the planar texture (Grandjean texture) of a cholesteric phase before irradiation of UV light. The optical texture rapidly changed from planar to fingerprint texture upon UV light irradiation (Fig. 2 (a-c)). Here, the helical axis (structural chirality axis) of a cholesteric LC in the planar texture is normal to the substrate. However, the helical axis in the fingerprint texture is parallel to the substrate. In fact, the helical axis of the cholesteric liquid crystal turned from normal to parallel with respect to the substrate by UV light because light-induced molecular re-orientation occurred during the isomerization process of $\mathrm{AZO}^{*}$ from trans to cis isomer in the LC matrix. Subsequently, the texture further turned into clear fingerprint structure, showing so-called cholesteric fingers (Fig. 2(d-f)). Further, the fingerprint 
Goto, H; Kawabata, K

Light driven asymmetric polymerization: an approach for tele-control reaction POLYMER CHEMISTRY (UK), 2(5), 1098-1106 (2011).

released again and isotropic regions were extended (Fig. 2(g)). Finally, the liquid crystal was transformed into isotropic phase because the cis isomer completely broke the LC order. Note that the Schlieren texture of a nematic phase was observed before a complete disappearance of the birefringence (Fig. 3(h)).

This behavior can be summarized in the following four steps: 1) planar texture; 2) change in helical axis direction; 3) transition from a cholesteric to nematic phase; and 4) transition from a nematic to isotropic phase. The change in the optical texture is derived from the isomerization process of trans-cis isomerization of $\mathrm{AZO}^{*}$ in the $\mathrm{LC}$ matrix. Repeating isomerization afforded distinct fingerprint texture under Vis light (Fig. $\mathrm{S} 2$, ESI $\dagger$ ). This result suggested that the cis/trans content in the entire system mechanically tunes the ordered state of the LC matrix. In other words, the particular quantity of the cis or trans isomer generated by light commands molecular orientation and mechanically induced phase transition for the entire LC system. The photo-induced phase transition by UV and Vis light irradiation repeated 5 times, respectively, showed no drop in performance, indicating good photostability. Good reversibility and reproducibility of azobenzenes have been proved by chemical motors. ${ }^{21}$ 
Goto, H; Kawabata, K

Light driven asymmetric polymerization: an approach for tele-control reaction POLYMER CHEMISTRY (UK), 2(5), 1098-1106 (2011).

\section{Preparation of cholesteric electrolyte solution}

An LC electrolyte solution containing monomer was prepared to perform an electrochemical polymerization in the LC. The addition of small amounts of an optically active molecule as a chiral dopant to the nematic LC can induce the formation of cholesteric LC with a 3-D helical structure on a mesoscopic level. ${ }^{16,17}$ Firstly, AZO* was added to 4-n-hexyl-4'-cyanobiphenyl (6CB) as a LC matrix. AZO* functions as both a chiral dopant and photo-isomerization dopant (ie., chiral photo-isomerization dopant). Furthermore, tetrabutyl ammonium perchlorate (TBAP, $\left.\left(\mathrm{C}_{4} \mathrm{H}_{9}\right)_{4} \mathrm{NClO}_{4}\right)$ was added to the electrolyte solutions as a supporting salt.

The constituents in the electrolyte solution for this electrochemical polymerization were as follows: 1) monomer (terEDOT or FFLF); 2) chiral photo-isomerization dopant $(\mathrm{AZO} *)$; 3) LC solvent (6CB); and 4) supporting salt (TBAP). The composition of the cholesteric LC electrolyte solutions (Elye-1, Elyte-2) and monomer structure are summarized in Table 1.

The LC electrolyte solution was heated to completely dissolve TBAP, monomer, and the dopant in 6CB. These electrolyte solutions containing monomer exhibit thermotropic LC behavior and a typical fingerprint texture under polarizing optical 
Goto, H; Kawabata, K

Light driven asymmetric polymerization: an approach for tele-control reaction POLYMER CHEMISTRY (UK), 2(5), 1098-1106 (2011).

microscopy $(\mathrm{POM})$ at room temperature. The distance between two stripes corresponds to the half-pitch of the helical periodicity.

\section{Electro-polymerization under irradiation}

Electro-polymerization in the cholesteric LC electrolyte solution creates a chiroptically active polymer with a characteristic fingerprint structure, which is very similar to that of a cholesteric liquid crystal. ${ }^{3}$ In this study, electro-polymerization of the monomers in LC electrolyte solution containing the azobenzene derivative was carried out under irradiation. The photo-isomerization dopant isomerizes from trans to cis upon UV irradiation. The photo-isomerization of the dopant induces a phase transition of the LC electrolyte solution from a cholesteric to isotropic phase. Therefore, light incident in the polymerization cell can tune structural chirality of the LC electrolyte solution. Thus, electro-polymerization in the LC electrolyte solution with photo-isomerization dopant allows optical tuning of the chiroptical activity of the polymer during the polymerization process.

Electro-polymerization was carried out with the sandwitch-cell LC polymerization method that the author previously developed. ${ }^{2}$ Prior to electrochemical polymerization, 
Goto, H; Kawabata, K

Light driven asymmetric polymerization: an approach for tele-control reaction POLYMER CHEMISTRY (UK), 2(5), 1098-1106 (2011).

the LC electrolyte solution was heated in a vial under an argon atmosphere in order to completely dissolve the supporting salt, the monomer, and the chiral photo-isomerization dopant in 6CB. The LC electrolyte was injected by the capillary technique between two sandwiched indium-tin-oxide (ITO) coated glass electrodes with a Teflon sheet (thickness $=0.2 \mathrm{~mm}$ ) used as a spacer (reaction cell). The reaction cell was initially heated (ca. $60{ }^{\circ} \mathrm{C}$ ), and then gradually cooled to room temperature. Then, irradiation with Vis or UV light was carried out while applying a $4.0 \mathrm{~V}$ across the cell. The polymerization was either carried out in the dark after UV irradiation, or the polymerization was performed under Vis light (Scheme 2). After $30 \mathrm{~min}$, an insoluble and infusible polymeric thin film was obtained, which coated the anode side of the ITO electrode. The film on the ITO was then washed with methanol, water, and acetone in that order, and dried to yield the polymer films.

Before polymerization of terEDOT, visual inspection of textural changes in the LC electrolyte solution containing the monomer (Elyte-1) was carried out in a thin glass cell. Fig. 3 shows an intermediate state of photo-isomerization for Elyte-1 observed with POM. The thickness of the cholesteric finger is extended (cholesteric finger corresponds to a helical half-pitch, and the length of half-pitch is extended) accompanied by the photo-isomerization upon UV light irradiation. The colorful texture completely 
Goto, H; Kawabata, K

Light driven asymmetric polymerization: an approach for tele-control reaction POLYMER CHEMISTRY (UK), 2(5), 1098-1106 (2011).

disappeared upon further irradiation with UV light.

Fig. 4(a) shows a differential interference optical microscopy (DIM) image of PterEDOT prepared in the cholesteric LC electrolyte solution containing AZO* under Vis light. The polymer surface shows a very similar structure to the exoskeleton microstructure of the littoral crab. ${ }^{18}$ The PterEDOT exhibited a fingerprint texture and possessed the fibril structure. The fingerprint shape indicated that the structural chirality axis of the polymer thus obtained was parallel to the substrate surface due to its alignment in the electric field applied during the electro-polymerization ${ }^{4}$ conducted under the environmental conditions that resulted in the fingerprint texture.

Fig. 4(b) displays the POM image of the polymer, showing a clear boundary. The left side of Fig. 4(b) shows the UV irradiation segment, while the Vis irradiation segment is on the right side. This area was optically masked during the UV light irradiation. The left side shows a sanded texture, while the right displays a fingerprint texture. Furthermore, the Schlieren texture and a micro-organism-like texture are observed for the sample prepared under UV light in intermediate isomerization states of the LC electrolyte solution, as shown Fig. S3 (ESI†).

Fig. 5 shows surface images of poly(2,7-di(2-furyl)fluorene) (PFFLF) prepared by the electro-polymerization in a cholesteric electrolyte solution containing AZO* (Elyte-2, 
Goto, H; Kawabata, K

Light driven asymmetric polymerization: an approach for tele-control reaction POLYMER CHEMISTRY (UK), 2(5), 1098-1106 (2011).

Table 1) under irradiation. The image in Fig.5(a) obtained with the DIM shows a characteristic labyrinthine convexo-concave structure of PFFLF prepared under Vis light irradiation. The SEM observation of the polymer supports this result, as shown in Fig. 5(b) and Fig. S4 (ESI†). These images suggest that transcription of the cholesteric LC order to PFFLF was carried out during the polymerization under Vis light. On the other hand, Fig. 5(c) (SEM image) shows predominantly a thread-like texture of nematic LC phase (and partially a fingerprint texture), which was produced by extension of the cholesteric helical pitch due to trans-cis photo-isomerization of AZO* upon UV light irradiation. Furthermore, completion of the photo-isomerization to cis-form of $\mathrm{AZO}^{*}$ produces a polymer with no characteristic texture.

\section{Infrared absorption spectroscopy}

Infrared (IR) absorption spectra of 6CB, AZO*, PterEDOT obtained by the $\mathrm{KBr}$ method are shown in Fig. S5, ESI†. The PterEDOT prepared under Vis light (PterEDOT (Vis)) and PterEDOT prepared after UV irradiation for $30 \mathrm{~min}$ (PterEDOT $\left(\mathrm{UV}_{30}\right)$ ) showed the same absorption bands, indicating that these polymers possessed the same chemical structure. The PterEDOTs displayed no characteristic absorption bands of 6CB (2227 
Goto, H; Kawabata, K

Light driven asymmetric polymerization: an approach for tele-control reaction POLYMER CHEMISTRY (UK), 2(5), 1098-1106 (2011).

$\mathrm{cm}^{-1}, v_{\mathrm{CN}}$, terminal CN group) and AZO* $\left(1252 \mathrm{~cm}^{-1}, v_{\mathrm{C}-\mathrm{N}=}\right)$. The IR measurements demonstrated that the present polymerization methods yielded pure polymers. These results also suggested that phase separation ${ }^{19}$ between the polymers and the matrix (dopants, 6CB) occurred during polymerization.

\section{Optical absorption}

Optical absorption spectra of the polymer films on ITO in the monomer-free $0.1 \mathrm{M}$ TBAP/acetonitrile solution during the application of voltage (vs. $\mathrm{Ag} / \mathrm{Ag}^{+}$reference electrode) were examined. Fig. S6 (ESI $\dagger$ ) shows these spectro-electrochemistry data for PterEDOT $\left(\mathrm{UV}_{30}\right)$. An optical absorption band due to the $\pi-\pi^{*}$ transition of the main chain is observable at around $500 \mathrm{~nm}$. The absorption intensity due to the $\pi-\pi *$ transition of the main chain decreased with increasing voltage, while the absorption band at $>800 \mathrm{~nm}$ strengthened, corresponding to generation of polarons (radical cation, doping band) on the main chain, which is a typical behavior for an electro-active polymer. In this case TBAP functions as an electro-dopant. The absorption intensities clearly changed between $-0.5 \mathrm{~V}$ (de-doping, reduced) and $+0.5 \mathrm{~V}$ (doping, oxidized). PterEDOT (Vis) showed the same tendency in the absorption spectra. 
Goto, H; Kawabata, K

Light driven asymmetric polymerization: an approach for tele-control reaction POLYMER CHEMISTRY (UK), 2(5), 1098-1106 (2011).

Fig. S7 (ESI†) shows reversible changes in absorption for PterEDOT (Vis) on ITO glass with repeated scanning between $-0.5 \mathrm{~V}$ and $+0.5 \mathrm{~V}$ vs. $\mathrm{Ag} / \mathrm{Ag}^{+}$as a reference electrode in a monomer-free $0.1 \mathrm{M} \mathrm{TBAP/acetonitrile} \mathrm{solution.} \mathrm{The} \mathrm{absorption} \mathrm{intensity}$ was monitored at $508 \mathrm{~nm}$ (the $\pi-\pi *$ transition of the main chain) and $852 \mathrm{~nm}$ (the polaron band). In the oxidation process at $+0.5 \mathrm{~V}$, the absorption intensity at $508 \mathrm{~nm}$ decreased, while that at $852 \mathrm{~nm}$ increased, whereas in the reduction process, the opposite trend was observed. These changes in absorption intensity were reproducible.

\section{Optical rotatory dispersion}

Optical rotatory power is one of the most interesting physical properties of asymmetric chemical materials. The plane of polarization of linearly polarized light is rotated in a chiral medium. This property of natural optical rotation of light is comparable to the Faraday effect in magnetic field and Kerr effect in electric field. Fig. 6 (a) shows changes in optical rotatory dispersion (ORD) for the PterEDOT (Vis) under application of voltage between $-0.5 \mathrm{~V}$ and $+0.5 \mathrm{~V}$ vs. $\mathrm{Ag} / \mathrm{Ag}^{+}$as a reference electrode in a monomer-free $0.1 \mathrm{M}$ TBAP/acetonitrile solution, demonstrating that the optical rotation of the polymer is controlled by the electrochemically applied voltage. Upon doping 
Goto, H; Kawabata, K

Light driven asymmetric polymerization: an approach for tele-control reaction POLYMER CHEMISTRY (UK), 2(5), 1098-1106 (2011).

when the applied voltage was increased, an optical rotation in the visible region corresponding to absorption band of the $\pi-\pi *$ transition of the main chain and optical rotation at long wavelengths were observed with an isosbestic point at around $720 \mathrm{~nm}$. This result indicates that the polymer is electro-chiroptically active, ie., redox-chiroptically active, and that the optical rotation is controlled by the electrochemical process.

The reversible inversion of the sign of the ORD in the redox process via change of the electronic state of the polymer indicated that the polymer forms a chiroptical structure, and that the chiroptical activity of the polymer can be changed by the external potential (Fig. 6 (b)). The electrochemical potential change in the polymer produces a precise electronic doping level, with resulting changes in its electronic state. Thus, it is possible to control the optical rotation of the polymer by applying the voltage electrochemically. This phenomenon can be referred to as a redox (doping-dedoping) -driven control of chiroptical activity. ${ }^{5}$ The ORD results demonstrated that the LC electrolyte solution possesing structural chirality provides a chiral environment for the present polymerization.

\section{Circular dichroism (CD)}


Goto, H; Kawabata, K

Light driven asymmetric polymerization: an approach for tele-control reaction POLYMER CHEMISTRY (UK), 2(5), 1098-1106 (2011).

Fig. 7 shows CD spectra of PterEDOTs at applied voltages from $-0.5 \mathrm{~V}$ to $+0.5 \mathrm{~V}$. The polymer displayed a bisignate split-type CD shape at low voltage (reduced state, dedoping). The $\mathrm{CD}$ isosbestic point is found at the absorption maximum due to $\pi-\pi^{*}$ transition of the main chain. This suggested that the polymer shows an exciton coupling pattern. The bisignate band in the reduced state suggests the presence of an intermolecular process upon aggregate formation. The exciton coupling requires the presence of an unconjugated chromophore in the chiral arrangement, which can occur through interchain interaction between individual main chains in the aggregate state. In this case, the aggregate-induced band can be a charge transfer-type $\pi$-stacking of the polymer backbone. $\mathrm{CD}$ in the oxidized state suggests partly released chiral aggregation due to intercalation of perchlorate ion between the main chains by the redox process. This result indicated that the polymer in the oxidized state also forms a chiral structure. The CD signals observed for the polymer can not be due to AZO* because the absorption band appears in the short-wavelength region $(<300 \mathrm{~nm})$. These spectra confirm electro-chiroptically active behavior of the polymers. PterEDOT(Vis) consistently displayed intensity changes in $\mathrm{CD}$ spectra during the application of the voltage. 
Goto, H; Kawabata, K

Light driven asymmetric polymerization: an approach for tele-control reaction POLYMER CHEMISTRY (UK), 2(5), 1098-1106 (2011).

On the other hand, the polymers prepared after UV irradiation for $30 \mathrm{~min}$ $\left(\right.$ PterEDOT $\left.\left(\mathrm{UV}_{30}\right)\right)$ showed weak signals and small changes in the $\mathrm{CD}$ intensity as compared to those of the polymer prepared under Vis light. In particular, PterEDOT $\left(\mathrm{UV}_{60}\right)$ made under $\mathrm{UV}$ irradiation for $60 \mathrm{~min}$ displayed relatively weak signals, indicating that the chiroptical activity was still present. This result demonstrates that the cis isomer of the photo-isomerization dopant generated under UV light disturbed the aggregation of structural chirality of the cholesteric LC. Polymerization in a depressed structural chiral field resulted in a decrease of optical activity for the resultant polymer. In other words, the external light tunes chiroptical activity during polymerization through tuning of structural chirality of the LC electrolyte solution. Fig. 8 shows reversible changes in the ellipticity of PterEDOT (Vis) and PterEDOT(UV $\left.\mathrm{U}_{30}\right)$ during repeated voltage scanning from $-0.5 \mathrm{~V}$ to $+0.5 \mathrm{~V}$ vs. $\mathrm{Ag} / \mathrm{Ag}^{+}$. In the oxidation process at $+0.5 \mathrm{~V}$, the $\mathrm{CD}$ band corresponding to the $\pi-\pi^{*}$ transition of the main chain in the visible region (PterEDOT (Vis): $457 \mathrm{~nm}$, PterEDOT(UV $\left.\mathrm{UV}_{30}\right): 444 \mathrm{~nm}$ ) decreased in intensity (Fig. 8(a,b)), while that at long wavelengths, corresponding to the doping band (PterEDOT (Vis): $658 \mathrm{~nm}$, PterEDOT(UV $\left.\mathrm{UV}_{30}\right): 600 \mathrm{~nm}$ ), intensified whereas the opposite trend was observed in the reduction process (Fig. 8(c,d)). These observed changes in the $\mathrm{CD}$ intensity were reproducible. The photo-isomerization during polymerization tunes 
Goto, H; Kawabata, K

Light driven asymmetric polymerization: an approach for tele-control reaction POLYMER CHEMISTRY (UK), 2(5), 1098-1106 (2011).

the chiroptical activity of resultant polymers. The polymer prepared in the electrolyte solution in a completely isotropic state showed no chiroptical activity. Note that the optical properties of the polymer films exhibited no changes for 1 month in the air, indicating good environmental stability.

\section{Diffraction}

PFFLF showed clear periodic convexo-concave structure. Laser transmission through the polymer film prepared from Elyte-2 under Vis light (PFELF(Vis)) produced a circular Fourier-transformed interference image with clear separation of red and green laser light (Fig. 9(a)) due to the random grating formed by the single-pitch helicity derived from stripes of the polymer. The red $(\lambda=670 \mathrm{~nm})$ and green $(\lambda=532 \mathrm{~nm})$ are projected to the outer and inner parts of the circular diffraction pattern, respectively. Upon irradiation with blue laser light at $473 \mathrm{~nm}$, the polymer displayed diffraction for $m$ $=1,2$, as shown in Fig 9(b). The convexo-concave structure of the PFFLF(Vis) produced iridescent reflection and diffraction of light. Although the natural color of the PFFLF is dark brown in the half-doped state, the polymer film exhibited a rainbow-like reflection upon irradiation at certain angles with incident white light (Fig.9(c)). This structural color originated from the helicity-based periodic convexo-concave structure 
Goto, H; Kawabata, K

Light driven asymmetric polymerization: an approach for tele-control reaction POLYMER CHEMISTRY (UK), 2(5), 1098-1106 (2011).

of the polymer surface, similar to photonic insects showing structural color. On the other hand, the polymers prepared after irradiation of UV light (PFFLF(UV)) showed neither the diffraction nor the rainbow color reflection because the polymers posessed no periodic surface structure. This result suggested that the polymerization method employed in this study allowed UV/Vis light-driven separation synthesis of polymers for use in optical diffraction applications.

\section{Plausible mechanism}

Scheme 3 illustrates photo-isomerization of AZO* upon light irradiation, changes in the optical texture of the LC electrolyte solution (Scheme 3(a,b)), and SEM image of the resultant LC-free PterEDOTs film surface (Scheme 3(c,d)). Trans isomer of the azobenzene derivative show good affinity for the LC medium, but the cis isomer mechanically deformed the chiral LC structure. The polymerization in the cholesteric phase of the LC medium containing the trans isomer of AZO* allowed production of a polymer having structural chirality and characteristic fingerprint texture with fibril structure via transcription from structural chirality of the cholesteric LC medium. However, polymerization in the isotropic phase of the LC medium produced by the cis isomer of the photo-isomerization dopant yielded no chiral LC-like texture. It can be 
Goto, H; Kawabata, K

Light driven asymmetric polymerization: an approach for tele-control reaction POLYMER CHEMISTRY (UK), 2(5), 1098-1106 (2011).

concluded that the external incident light can induce tuning of chiroptical activity of the resultant polymer through tuning of the photo-induced phase transition of the LC electrolyte solution in the polymerization reaction.

\section{Conclusions}

The azobenzene derivative, AZO*, plays roles as both chiral dopant and photo-isomerization dopant. Photo-induced phase transition of $\mathrm{AZO}^{*}$ in the LC electrolyte solution allows chiroptical activity tuning during polymerization. This study suggests a viable approach for tele-commandable asymmetric chemical reaction.

\section{Experimental}

\section{Synthesis}

\section{(S)-(+)-4-Butyl-[4-(1-methyl-heptyloxy)-azobenzene] (AZO*).}

A solution of diethylazodicarboxylate (DEAD) in toluene $(3.57 \mathrm{~g}, 2.2 \mathrm{~mol} / \mathrm{L})$ was slowly added to another solution of 4-butyl-4'-hydroxyazobenzene (2g, $7.86 \mathrm{mmol})$, (R)-(-)-2-octanol (1.02 g, $7.86 \mathrm{mmol})$, and triphenylphosphine (TPP, $2.06 \mathrm{~g}, 7.86$ 
Goto, H; Kawabata, K

Light driven asymmetric polymerization: an approach for tele-control reaction POLYMER CHEMISTRY (UK), 2(5), 1098-1106 (2011).

mmol) in $20 \mathrm{~mL}$ of THF at room temperature. The mixture was stirred for $24 \mathrm{~h}$. Then, the solution was evaporated and washed with water thoroughly, and extracted by $\mathrm{CH}_{2} \mathrm{Cl}_{2}$. The organic layer was evaporated. The crude product was purified with column chromatography (silica gel, $\mathrm{CH}_{2} \mathrm{Cl}_{2}$ ) to afford $0.92 \mathrm{~g}$ of red liquid $(\mathrm{Y}=31.9 \%)$. $[\alpha]_{\mathrm{D}}{ }^{25}=$ +8.35 deg $\left(\mathrm{CHCl}_{3}\right) .{ }^{1} \mathrm{H}$ NMR (400 MHz, $\delta$ from TMS, $\left.\mathrm{CDCl}_{3}\right), 0.87(3 \mathrm{H}, \mathrm{t}, J=6.9 \mathrm{~Hz}$, $\left.\mathrm{CH}_{3}\right), 0.93\left(3 \mathrm{H}, \mathrm{t}, J=7.4 \mathrm{~Hz}, \mathrm{CH}_{3}\right), 1.39\left(14 \mathrm{H}, \mathrm{m}, \mathrm{CH}_{2} \mathrm{x}\right.$ 7), 1.54-1.78 (4H, m, $\mathrm{CH}_{2} \mathrm{x}$ 2), $2.66\left(2 \mathrm{H}, \mathrm{t}, J=7.8 \mathrm{~Hz}\right.$, ph- $\left.\mathrm{CH}_{2}\right), 4.37\left(1 \mathrm{H}, J=5.9 \mathrm{~Hz}\right.$, sext, ph-C*H($\left.\left(\mathrm{CH}_{2}\right)\right), 6.96$ $(2 \mathrm{H}, \mathrm{dd}, J=9.2 \mathrm{~Hz}, \mathrm{ph}), 7.28(2 \mathrm{H}, \mathrm{d}, J=8.2 \mathrm{~Hz}, \mathrm{ph}), 7.80(2 \mathrm{H}, \mathrm{d}, J=8.2 \mathrm{~Hz}, \mathrm{ph}), 7.88$ $(2 \mathrm{H}, \mathrm{dd}, J=7.9 \mathrm{~Hz}, \mathrm{ph}) .{ }^{13} \mathrm{C} \mathrm{NMR}\left(100 \mathrm{MHz}, \delta\right.$ from TMS, $\left.\mathrm{CDCl}_{3}\right), 13.93,14.07$, $19.69,22.33,22.58,25.46,29.25,31.77,33.46,35.53,36.40,74.13,115.67,122.46$, $124.55,128.96,145.59,146.72,151.00,160.59$.

\section{2,7-Di(2-furyl)fluorene (FFLF) ${ }^{20}$}

A solution of 2-(tributylstannyl)furan $(6.7 \mathrm{mmol})$ and 2,7-dibromofluorene (3.4 mmol) in toluene $(8 \mathrm{~mL})$ was stirred for $30 \mathrm{~min}$ at $90{ }^{\circ} \mathrm{C}$. Then, $\mathrm{Pd}\left(\mathrm{PPh}_{3}\right)_{4}(0.067 \mathrm{mmol})$ was added to the solution and stirred for $24 \mathrm{~h}$ at $90{ }^{\circ} \mathrm{C}$. The solution was filtered, and the filtrate was evaporate. The crude product was purified with column chromatograph 
Goto, H; Kawabata, K

Light driven asymmetric polymerization: an approach for tele-control reaction POLYMER CHEMISTRY (UK), 2(5), 1098-1106 (2011).

(silica gel, $\mathrm{CH}_{2} \mathrm{Cl}_{2}$ ) and recrystalized from $\mathrm{CH}_{2} \mathrm{Cl}_{2}$. The material was dried under vacuo to yield $0.87 \mathrm{~g}(2.9 \mathrm{mmol}) . \mathrm{Y}=88 \% .{ }^{1} \mathrm{H} \mathrm{NMR}\left(270 \mathrm{MHz}, \delta\right.$ from TMS, $\left.\mathrm{CDCl}_{3}\right) 3.97(\mathrm{~s}$, 2H, C(fl) $\left.H_{2}\right), 6.50\left(\mathrm{~m}, 2 \mathrm{H}, \mathrm{C}\left(\mathrm{fu} 4,4^{\prime}\right) H\right), 6.69\left(\mathrm{~d}, 2 \mathrm{H}, \mathrm{C}\left(\mathrm{fu} 3,3^{\prime}\right) H, J=3.3 \mathrm{~Hz}\right), 7.49(\mathrm{~s}, 2 \mathrm{H}$, C(fu5, 5')H), $7.74(\mathrm{~m}, 4 \mathrm{H}, \mathrm{C}(\mathrm{fl} 3,4,7,8) H), 7.86(\mathrm{~s}, 2 \mathrm{H}, \mathrm{C}(\mathrm{fu} 1,10) H)$.

\section{Constituent of LC electrolyte solution containing monomer}

Elyte-1. terEDOT (3 mg), 6CB (0.5 g), TBAP (1.7 mg), AZO* (25 mg).

Elyte-2. FFLF (10 mg), 6CB (0.5 g), TBAP (2 mg), AZO* (50 mg).

\section{Materials}

2-(Tributylstannyl)furan (TCI, Tokyo Chemical Industry), and 2,7-dibromofluorene (TCI) were used as received. High-purity chloroform (Wako) was used without purification for optical measurements of the polymers. Toluene, THF (Wako Pure Chemical Industries), and EDOT (Aldrich) were purified with distillation prior to use. TBAP and cholesteryl nonanoate were obtained from Tokyo Kasei (TCI) Japan. 6CB was purchased from Merck. The ITO glass (Furuuchi Chemical Corporation) consists of a ca.12 $\mathrm{nm}$-thick ITO layer on glass $\left(9 \Omega \mathrm{cm}^{2}\right)$. 
Goto, H; Kawabata, K

Light driven asymmetric polymerization: an approach for tele-control reaction POLYMER CHEMISTRY (UK), 2(5), 1098-1106 (2011).

\section{Techniques}

All synthetic experiments (synthesis of monomers) were performed under an argon atmosphere using Schlenk/vacuum line techniques. ${ }^{1} \mathrm{H}$ NMR spectra were measured in $\mathrm{CDCl}_{3}$ using a Bruker AV-600 FT-NMR spectrometer or JASCO 270MHz EX-270 spectrometer. Chemical shifts were recorded in parts per million downfield from tetramethylsilane (TMS) as an internal standard. Absorption spectra were obtained using a UV-Vis spectrophotometer (Hitachi U-2000). Circular dichroism and optical rotation measurements were performed using a Jasco J-720 spectrometer with an ORDE-307W ORD unit. Electrochemical measurements of polymers were conducted using an electrochemical analyser ( $\mu$ Autolab III, Autolab, Netherlands), and optical textures were observed using a high-resolution polarizing microscope (Nikon ECLIPS LV 100) with a Nikon LU Plan Fluor and Nikon CFIUW lenses without oil immersion. Helical twisting power $\beta$ was obtained with Grandjean-Cano-wedge cell (EHC). UV light was generated with a UV lamp with an optical filter a $365 \mathrm{~nm}$ or a power-light emitting diode (LED, Nichia Chem.. Co. NCSU033A). SEM images were obtained with JEOL JSM-521. 
Goto, H; Kawabata, K

Light driven asymmetric polymerization: an approach for tele-control reaction POLYMER CHEMISTRY (UK), 2(5), 1098-1106 (2011).

\section{Acknowledgment}

The author is grateful to the Engineering Workshop of the University of Tsukuba for glasswork. NMR measurements were carried out by the Chemical Analysis Division of the Research Facility Center for Science and Technology, University of Tsukuba. This research was supported by Japan Society for the Promotion of Science (JSPS),

Grant-in-Aid for Scientific Research (C), 22550161.

\section{References}

1. P. Beaujuge, S. Ellinger, J.R. Reynolds, Nature Mater., 2008, 7, 795-799.

2. (a) H. Yoneyama, K. Kawabata, A. Tsujimoto, H. Goto, Electrochem. Commun., 2008, 10, 965-969; (b) H. Goto, Res. Lab. Note., University of Tsukuba, 2000, 24, 2401 (2 Dec, 2000).

3. H. Goto, J. Mater. Chem., 2009, 19, 4914-4921.

4. H. Goto, S. Nimori, J. Mater. Chem., 2010, 20, 1891-1898.

5. (a) H. Goto, Phys. Rev. Lett., 2007, 98, 253901, (b) H. Goto, Res. Lab. Note., University of Tsukuba, 2004, 30, 3100 (27 June, 2004).

6. K. Ichimura, M. Kidowaki, H. Akiyama, K. Kudo, V. Strehmel, B. Strehmel, Macromol. Rapid Commun., 1996, 17, 545-551. 
Goto, H; Kawabata, K

Light driven asymmetric polymerization: an approach for tele-control reaction POLYMER CHEMISTRY (UK), 2(5), 1098-1106 (2011).

7. K. Uchida, N. Izumi, S. Sukata Y. Kojima, S. Nakamura, M. Irie, Angew. Chem. Int. Ed., 2006, 45, $6470-6473$.

8. A. E. Seago, P. Brady, J.-P. Vigneron, T, D, Schultz, J. R. Soc. Interface, 2009 6, S165-S184.

9. A.C. Neville, "Biology of Fibrous Composites", Cambridge University Press, 1993.

10. S.-J. Lee, Y.-A. Son, H.-J. Suh, D.-N. Lee, S.-H. Kim, Dyes Pigm, 2006, 69, 18-21.

11. Y. Norikane, R. Davis, Y. Nishimura, T. Arai, N. Tamaoki, J. Photochem. Photobiol. A: Chem., 2009, 205, 116-121.

12. (a) K. Uchida, N. Nishikawa, N. Izumi, S. Yamazoe, H. Mayama, Y. Kojima, S. Yokojima, S. Nakamura, K. Tsujii, M. Irie, Angew. Chem. Int., 2010, 49, 5942-5944; (b) M. Ihie, M. Mohri, J. Org. Chem., 1988, 53, 803-808.

13. O. Mitsunobu, M Yanada, Bull. Chem. Soc. Jpn., 1967, 40, 2380-2382.

14. R. Cano, Bull. Soc. fr. Minéral. Cristrallogr., 1968, 91, 20.

15. (a) M. Kosugi, K. Sasazawa, Y. Shimizu, T. Migita, Chem. Lett., 1977, 301-302. (b) D. Milstein, J. K. Stille, J. Am. Chem. Soc., 1978, 100, $3636-3638$.

16. G. Solladie', G. Zimmermann, Angew. Chem. Int. 1984, 23, 348-362.

17. N. P. M. Huck, W. F. Jaeger, B. Lange, B. L. Fringe, Science, 1996, 273, 
Goto, H; Kawabata, K

Light driven asymmetric polymerization: an approach for tele-control reaction POLYMER CHEMISTRY (UK), 2(5), 1098-1106 (2011).

$1686-1688$.

18. Y. Bouligand, Tissue Cell, 1972, 4, 189-190, 192-217.

19. H. Kihara, T. Miura, R. Kishi, A. Kaito, Polymer, 2004, 45, 6357-6363.

20. K. Kawabata, H. Goto, Chem, Lett., 2009, 38, 706-707.

21. M. Yamada, M. Kondo, J. Mamiya, Y. Yu, M. Kinoshita, C. J. Barrett, T. Ikeda, Angew. Chem. Int. Ed. 2008, 47, 4986 -4988. 
Goto, H; Kawabata, K

Light driven asymmetric polymerization: an approach for tele-control reaction POLYMER CHEMISTRY(UK), 2(5), 1098-1106 (2011).
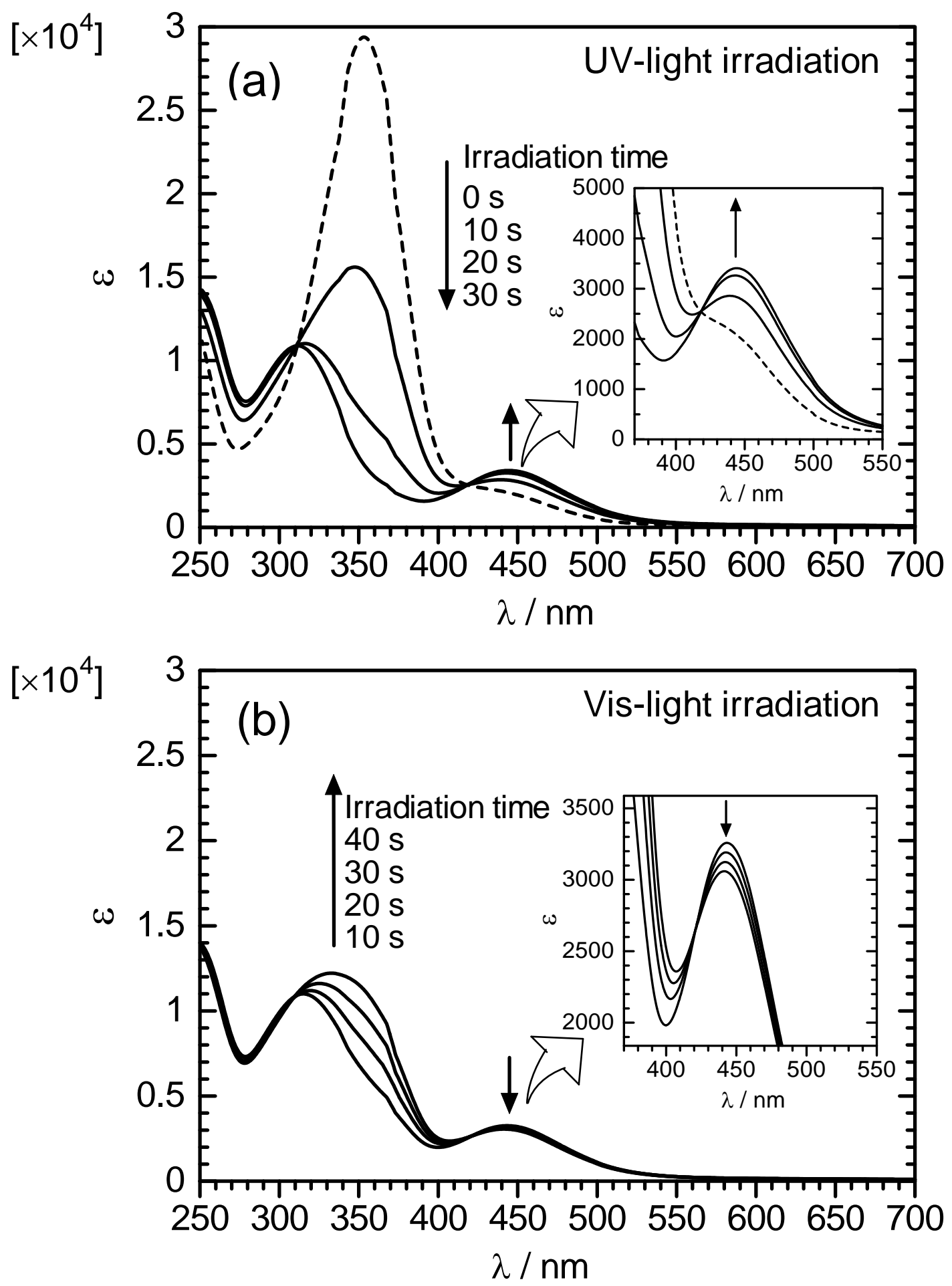

Fig. 1 Changes in optical absorption spectra of AZO* in chloroform solution during irradiation of light. (a) UV irradiation (trans-cis isomerization). (b) Vis irradiation following UV irradiation (cis-trans isomerization). Insets show spectra at higher magnification. 
Goto, H; Kawabata, K

Light driven asymmetric polymerization: an approach for tele-control reaction POLYMER CHEMISTRY(UK), 2(5), 1098-1106 (2011).

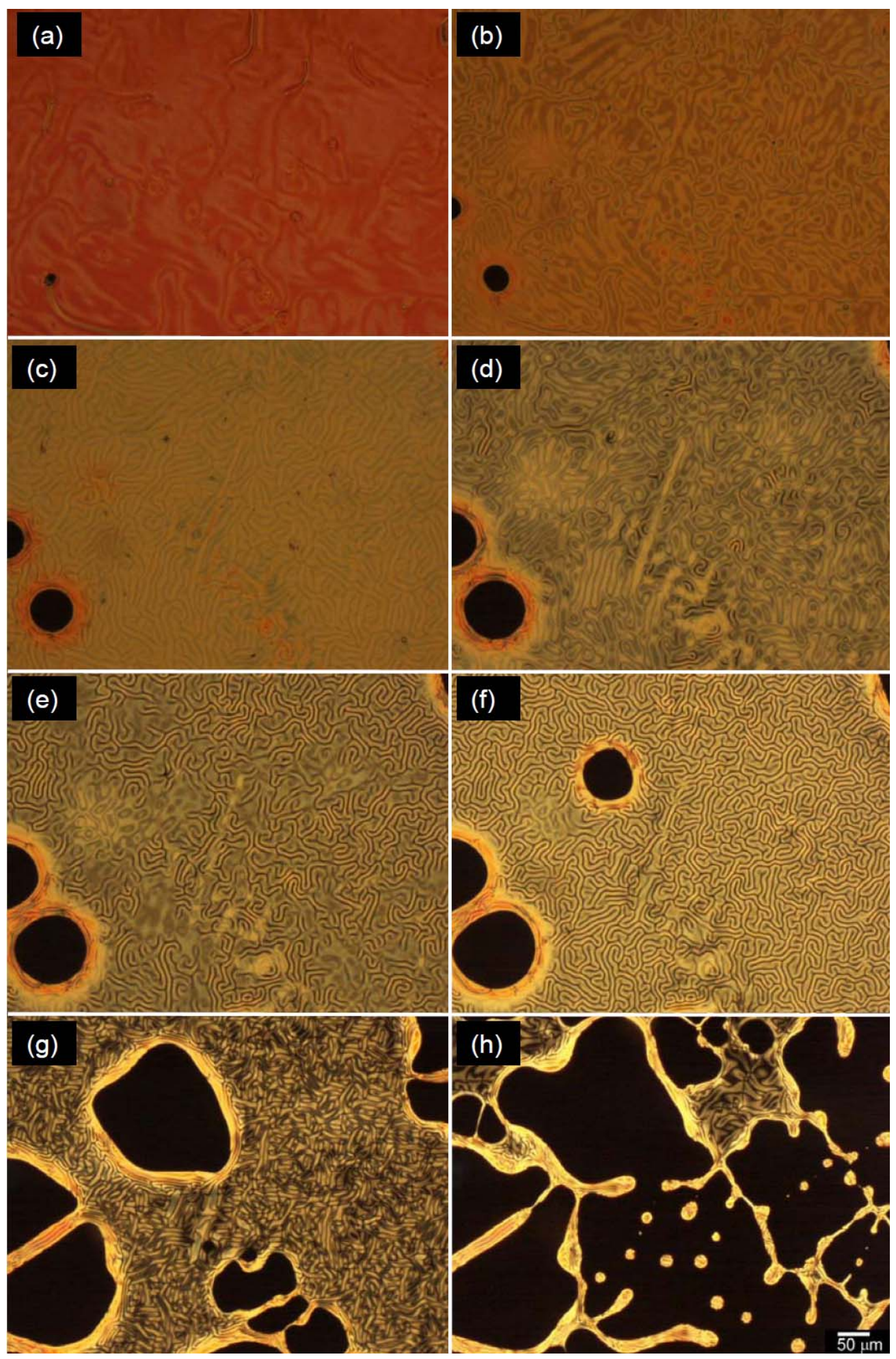

Fig. 2 Changes in polarizing optical microscopic images of a cholesteric mixture containing AZO* under irradiation of UV light for (a) $0 \mathrm{~s}$, (b) $4 \mathrm{~s}$, (c) $10 \mathrm{~s}$, (d) $14 \mathrm{~s}$, (e) $18 \mathrm{~s}$, (f) $20 \mathrm{~s}$, (g) $24 \mathrm{~s}$, (h) $26 \mathrm{~s}$ at $25^{\circ} \mathrm{C}$ from cholesteric LC state. 
Goto, H; Kawabata, K

Light driven asymmetric polymerization: an approach for tele-control reaction POLYMER CHEMISTRY(UK), 2(5), 1098-1106 (2011).

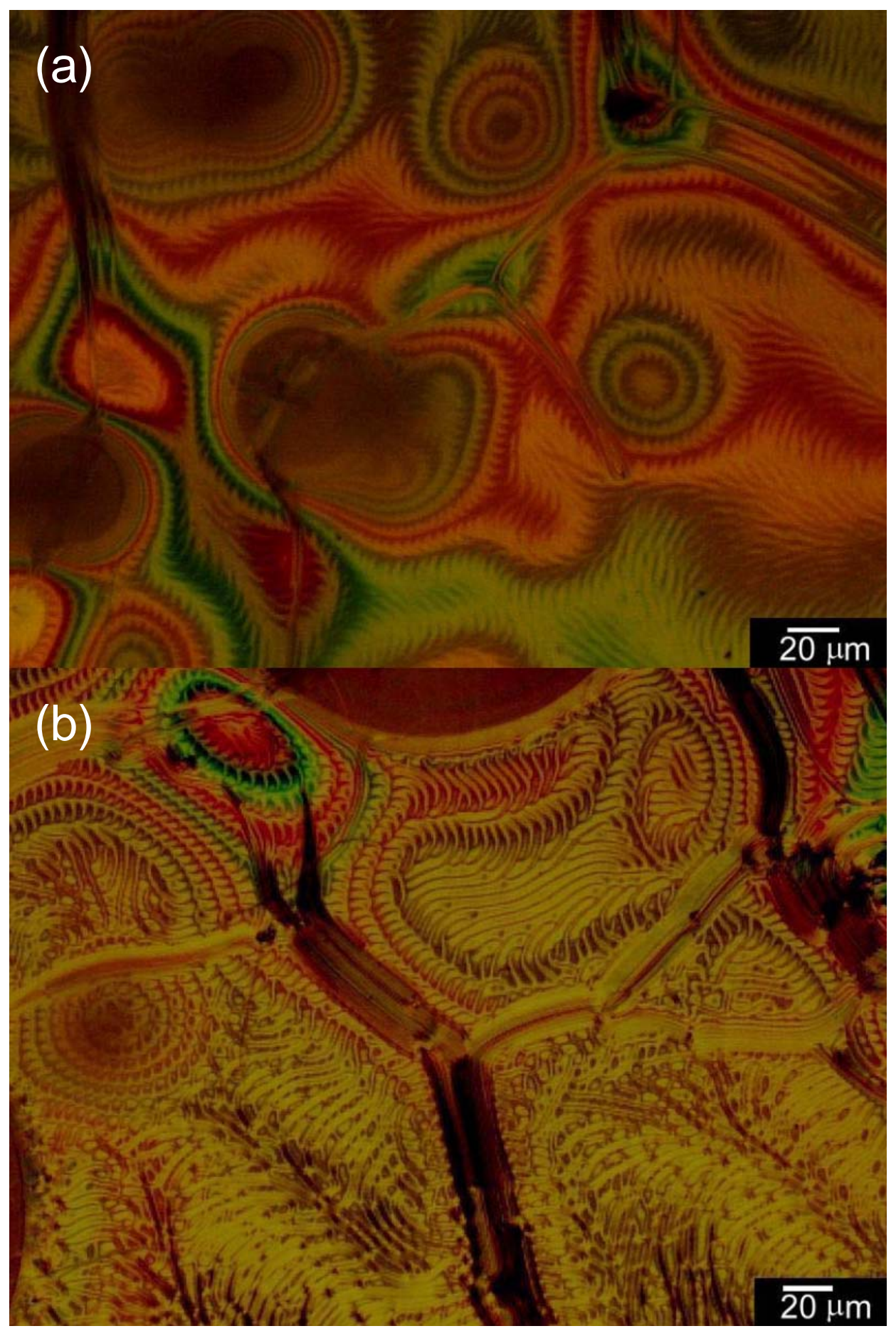

Fig. 3 POM images of Elyte-1 (Table 1) at intermediate state of photo-induced transition from cholesteric to isotropic phase under UV irradiation. 
Goto, H; Kawabata, K

Light driven asymmetric polymerization: an approach for tele-control reaction POLYMER CHEMISTRY (UK), 2(5), 1098-1106 (2011).
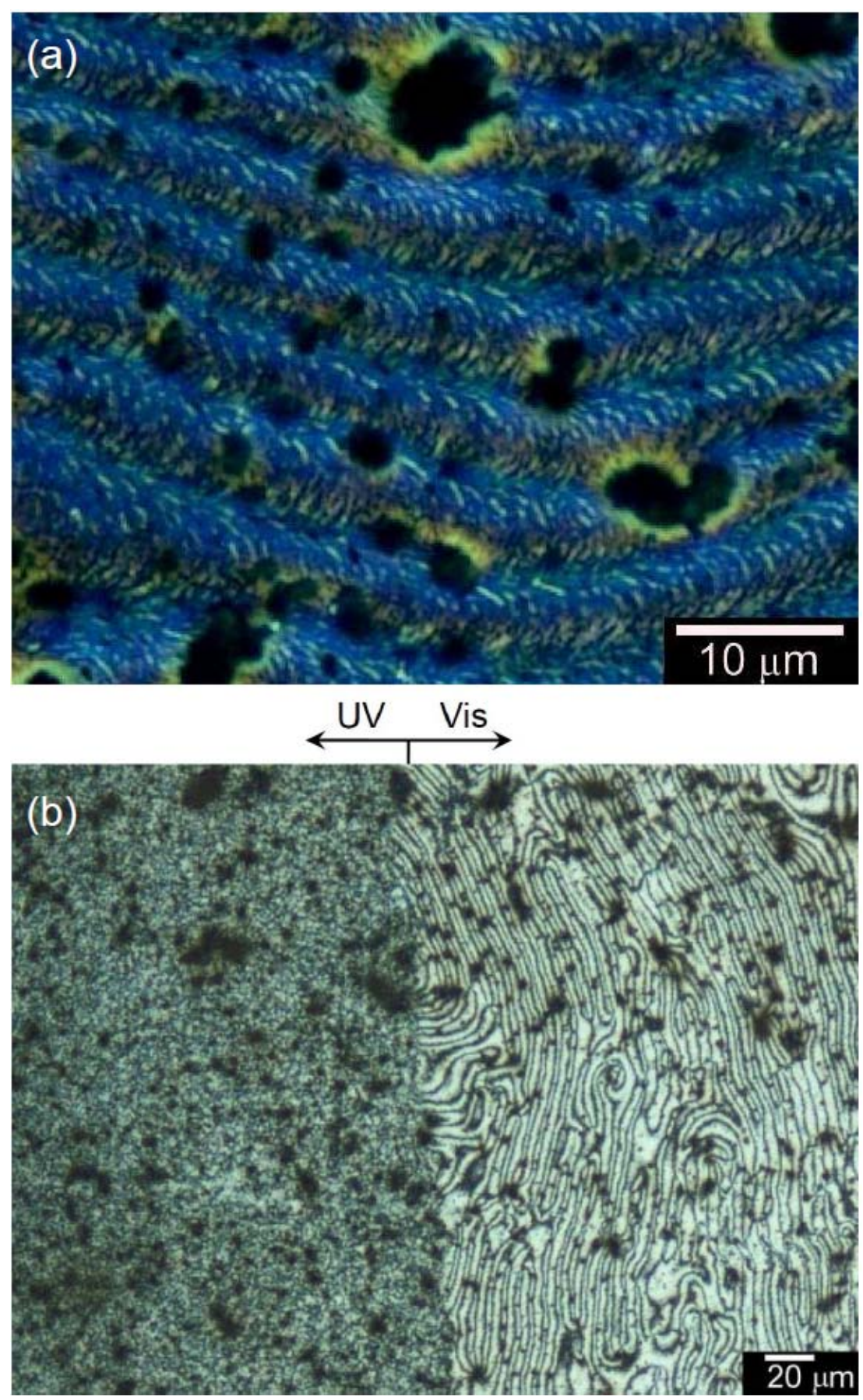

Fig. 4 (a) Differential interference optical microscopic (DIM) image of PterEDOT prepared in cholesteric LC electrolyte solution under the Vis light. (b) Polarizing optical microscopic image (POM) of PterEDOT prepared by electro-polymerization in the cholesteric liquid crystal solution containing chiral photo-isomerization dopant (AZO*) showing clear boundary. (Left side) The polymer prepared after irradiation of UV light for 30 min. (Right side) The polymer prepared under Vis light (this area was optically masked during the irradiation by UV light). 
Goto, H; Kawabata, K

Light driven asymmetric polymerization: an approach for tele-control reaction POLYMER CHEMISTRY(UK), 2(5), 1098-1106 (2011).

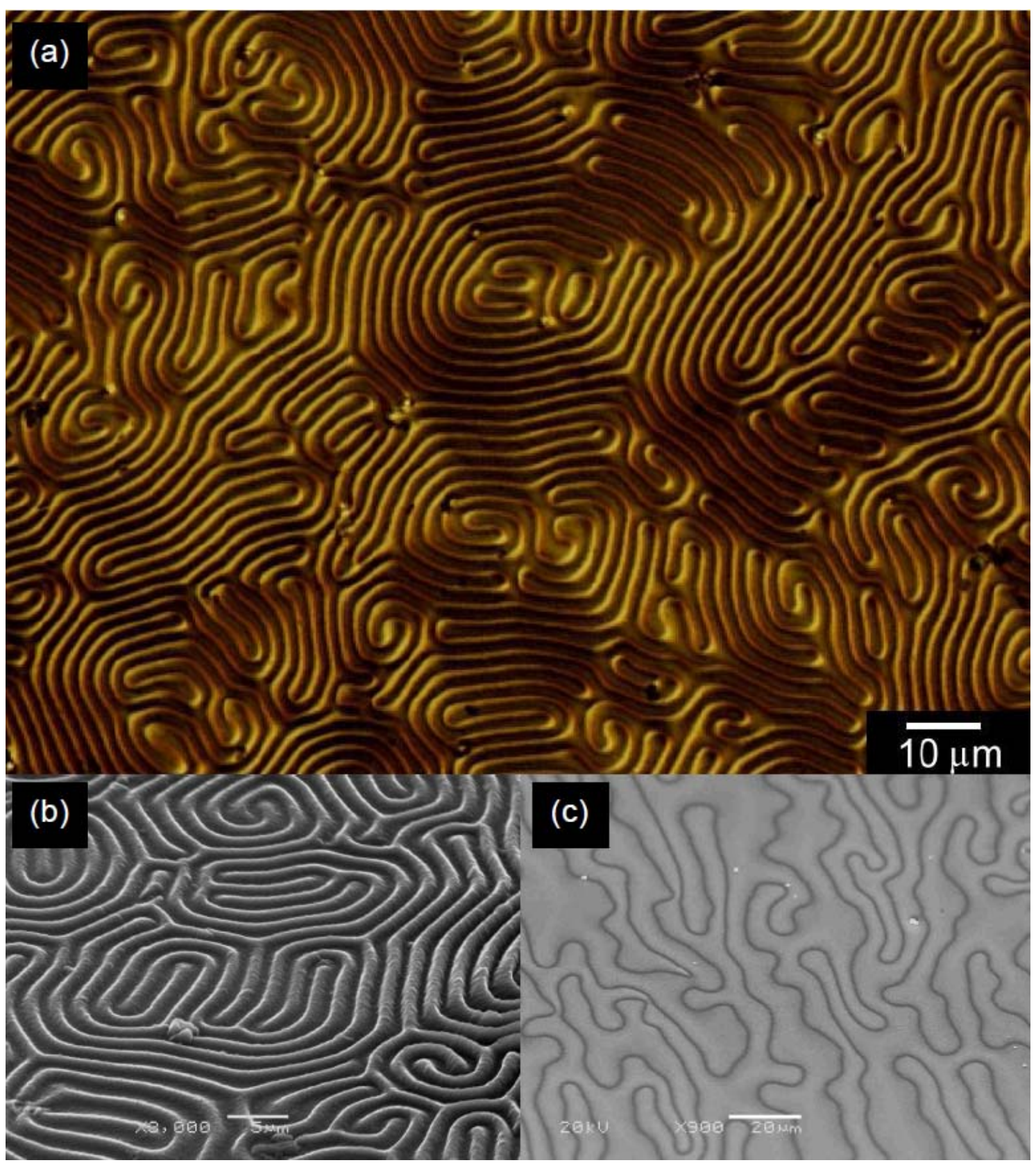

Fig. 5 Surface images of poly(furan-fluorene-furan, PFFLF) prepared by electrochemical polymerization in the cholesteric liquid crystal solution containing a chiral photo-isomerization dopant (AZO*). (a) Differential interference microscopic (DIM) image of PFFLF. (b) Scanning electron microscopic (SEM) image of PFFLF. (c) SEM image of the polymer obtained after irradiation by UV light. 
Goto, H; Kawabata, K

Light driven asymmetric polymerization: an approach for tele-control reaction POLYMER CHEMISTRY (UK), 2(5), 1098-1106 (2011).
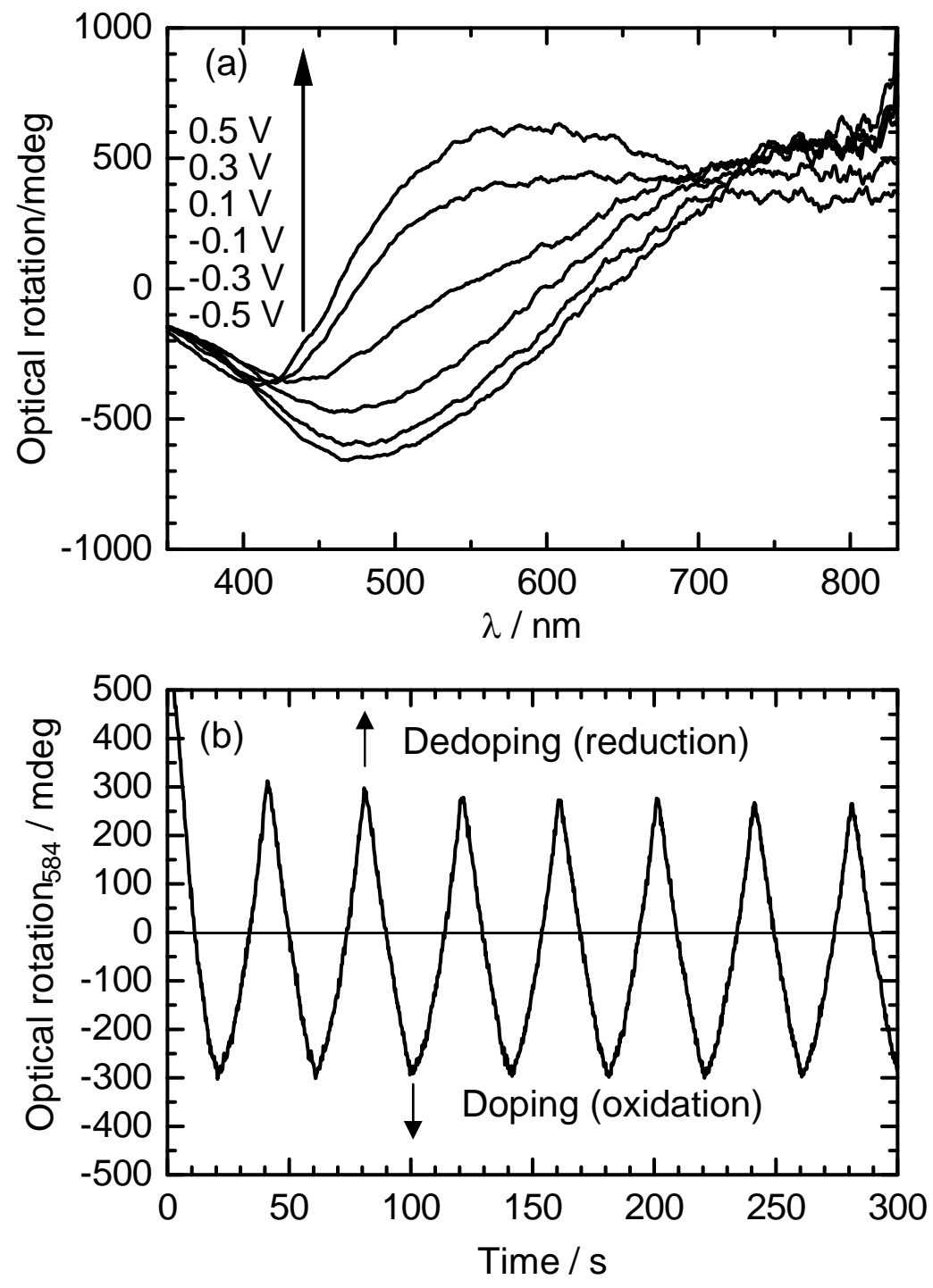

Fig. 6 (a) Optical rotatory dispersion (ORD) spectra of PterEDOT prepared in cholestreric LC under Vis light (PterEDOT (Vis)) at various potentials. (b) Reversible change in the optical rotation at $584 \mathrm{~nm}$ with electrochemical doping-dedoping cycle in monomer-free $0.1 \mathrm{M}$ TBAP/acetonitrile solution $(50 \mathrm{mV} / \mathrm{s})$. 
Goto, H; Kawabata, K

Light driven asymmetric polymerization: an approach for tele-control reaction POLYMER CHEMISTRY (UK), 2(5), 1098-1106 (2011).
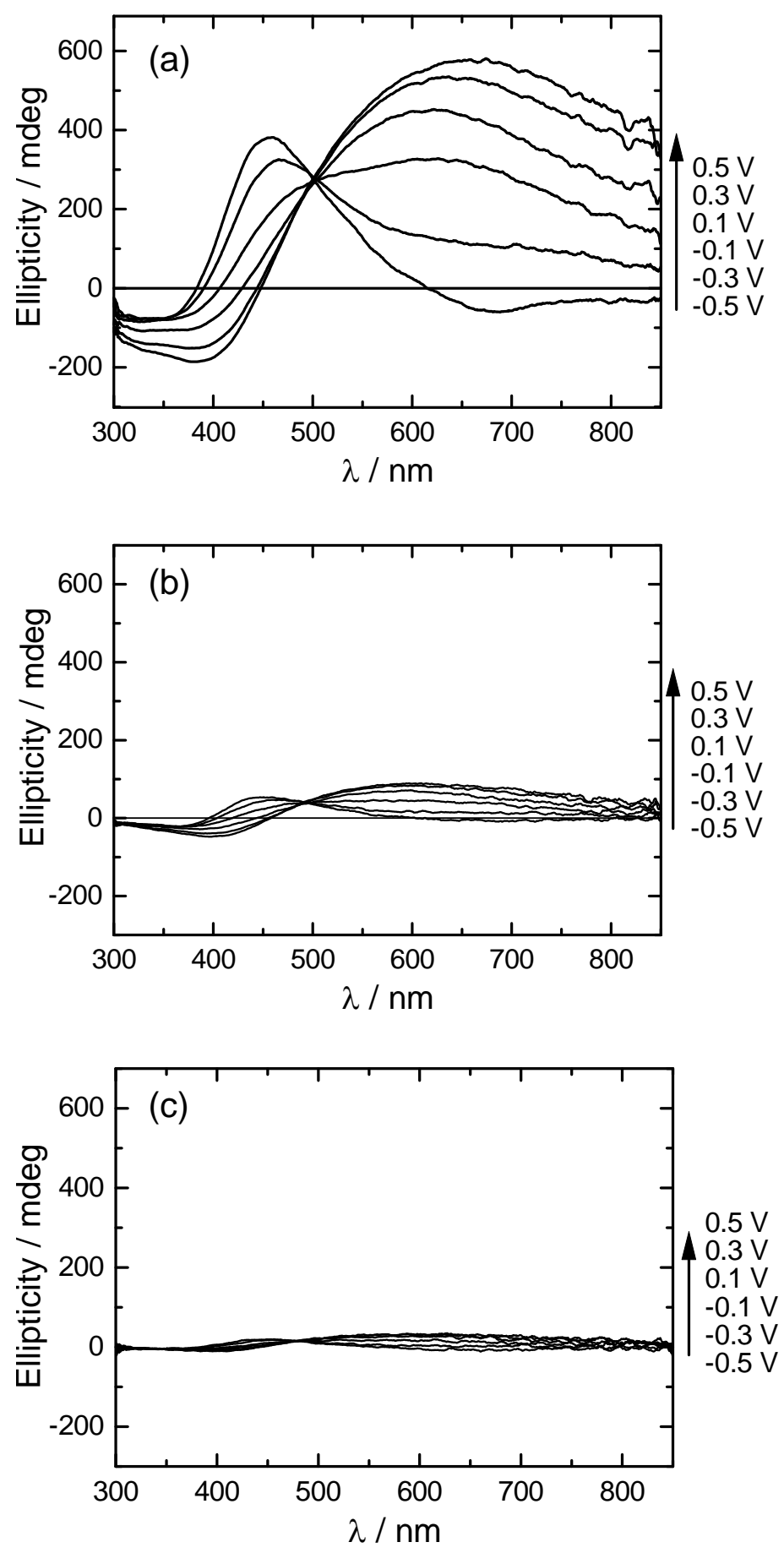

Fig. 7 CD spectra of PterEDOTs during voltage application. (a) PterEDOT prepared in cholesteric LC under Vis light. (b) PterEDOT prepared in cholesteric LC after UV light irradiation for $30 \mathrm{~min}$ (PterEDOT $\left(\mathrm{UV}_{30}\right)$ ). (c) PterEDOT prepared in cholesteric LC after UV light irradiation for $60 \mathrm{~min}\left(\operatorname{PterEDOT}\left(\mathrm{UV}_{60}\right)\right)$. 
Goto, H; Kawabata, K

Light driven asymmetric polymerization: an approach for tele-control reaction POLYMER CHEMISTRY (UK), 2(5), 1098-1106 (2011).
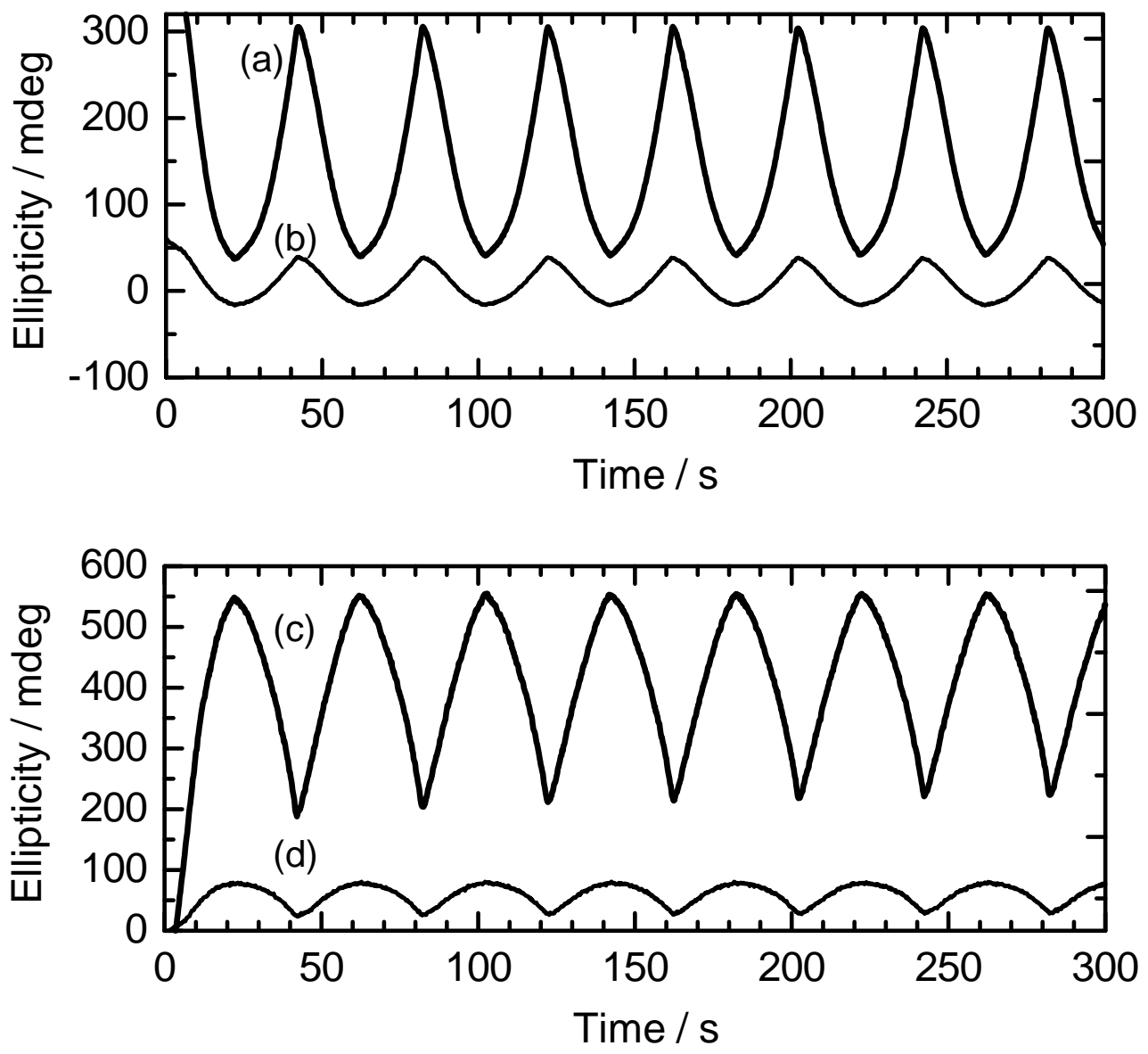

Fig. 8 Reversible changes in the ellipticity of PterEDOT (Vis) and PterEDOT(UV 30$)$ during repeated voltage scanning from $-0.5 \mathrm{~V}$ to $+0.5 \mathrm{~V}$ vs. $\mathrm{Ag} / \mathrm{Ag}^{+}$. (a) Changes in ellipticity of PterEDOT (Vis) (polymer prepared under Vis light irradiation) at $457 \mathrm{~nm}$ (absorption of $\pi-\pi^{*}$ transition of the main chain). (b) Changes in ellipticity of PterEDOT (PterEDOT $\left(\mathrm{UV}_{30}\right)$ ) at $444 \mathrm{~nm}$ (absorption of $\pi-\pi^{*}$ transition of the main chain). (c) Changes in ellipticity of PterEDOT (Vis) at $658 \mathrm{~nm}$ (the doping band, the polaron band). (d) Changes in ellipticity of PterEDOT( $\left(\mathrm{UV}_{30}\right)$ at $600 \mathrm{~nm}$ (the doping band, the polaron band). 
Goto, H; Kawabata, K

Light driven asymmetric polymerization: an approach for tele-control reaction POLYMER CHEMISTRY (UK), 2(5), 1098-1106 (2011).

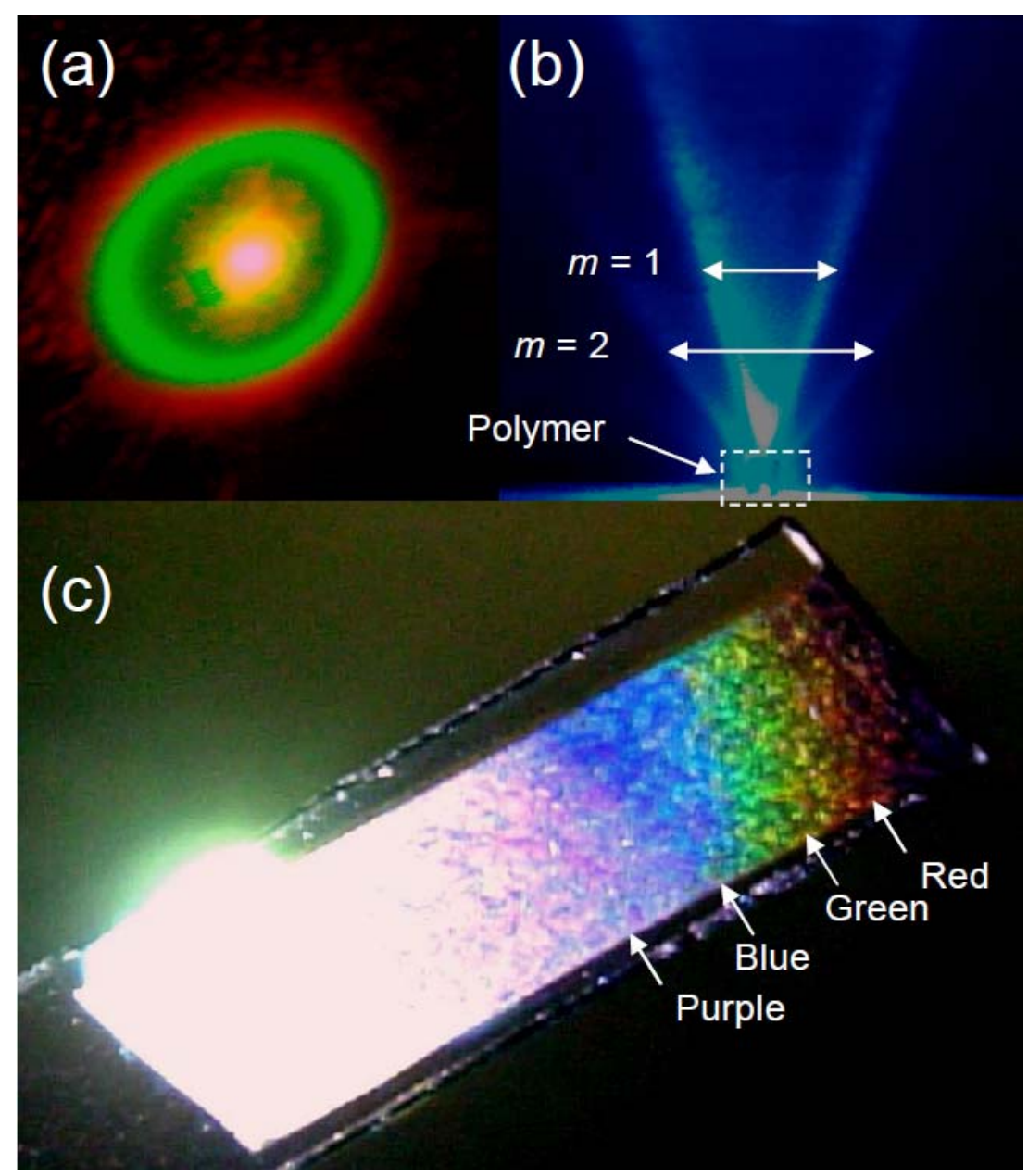

Fig. 9. (a) Diffraction pattern under irradiation with combined red and green laser light for PFFLF. (b) Blue diffraction of PFFLF(Vis) at normal incidence. (c) Polymer film on ITO under white light showing iridescence with purple, blue, green, and red reflections. 
Goto, H; Kawabata, K

Light driven asymmetric polymerization: an approach for tele-control reaction POLYMER CHEMISTRY(UK), 2(5), 1098-1106 (2011).

Table 1. Constituents of photo-isomerizable liquid crystal electrolyte solution containing monomers.

Electrolyte
solution

${ }^{\mathrm{a}}$ Supporting salt $=\left(\mathrm{C}_{4} \mathrm{H}_{9}\right)_{4} \mathrm{NClO}_{4}$ (tetrabutylammonium perchlorate, TBAP). 
Goto, H; Kawabata, K

Light driven asymmetric polymerization: an approach for tele-control reaction POLYMER CHEMISTRY(UK), 2(5), 1098-1106 (2011).

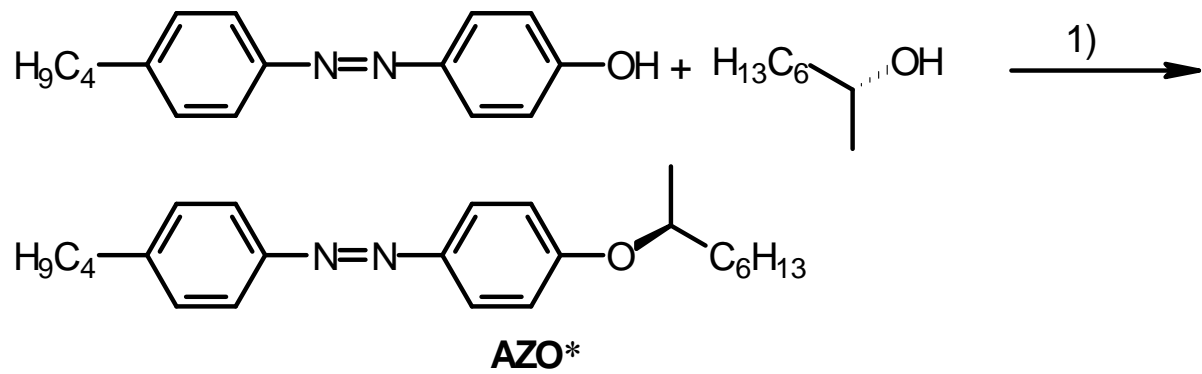

Scheme 1. Synthesis of photo-isomerization dopants. 1) Diethyl azodicarboxylate, (DEAD), triphenylphosphine (TPP), tetrahydrofuran (THF). 
Goto, H; Kawabata, K

Light driven asymmetric polymerization: an approach for tele-control reaction POLYMER CHEMISTRY (UK), 2(5), 1098-1106 (2011).
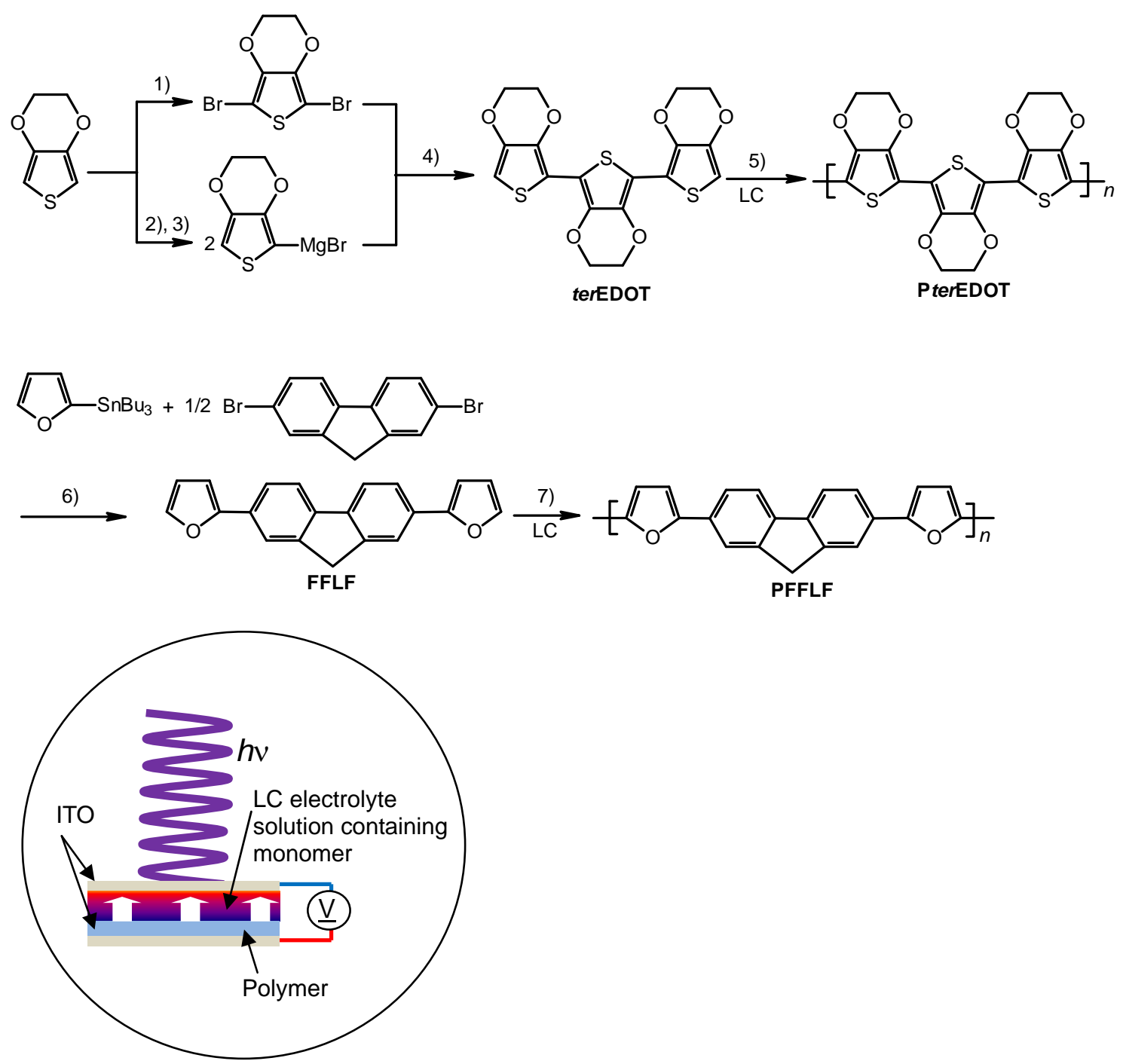

Scheme 2 Synthesis of monomers and polymers. 1) $N$-bromosuccinimide (NBS), $\mathrm{CHCl}_{3} /$ glacial acetic acid. ${ }^{3}$ 2) $n$-BuLi, tetrahydrofuran (THF). 3) $\mathrm{MgBr}_{2} \cdot \mathrm{Et}_{2} \mathrm{O}$. 4) $\mathrm{Ni}(\mathrm{dppp}) \mathrm{Cl}_{2}$, THF. 4) Electro-polymerization under UV or Vis light in LC electrolyte solution. 6) $\mathrm{Pd}\left(\mathrm{PPh}_{3}\right)_{4}$, tetrahydrofuran. 7) Electro-polymerization under UV or Vis light in LC electrolyte solution. LC = liquid crystal. Illustration shows polymerization cell with incident light. 
Goto, H; Kawabata, K

Light driven asymmetric polymerization: an approach for tele-control reaction POLYMER CHEMISTRY(UK), 2(5), 1098-1106 (2011).

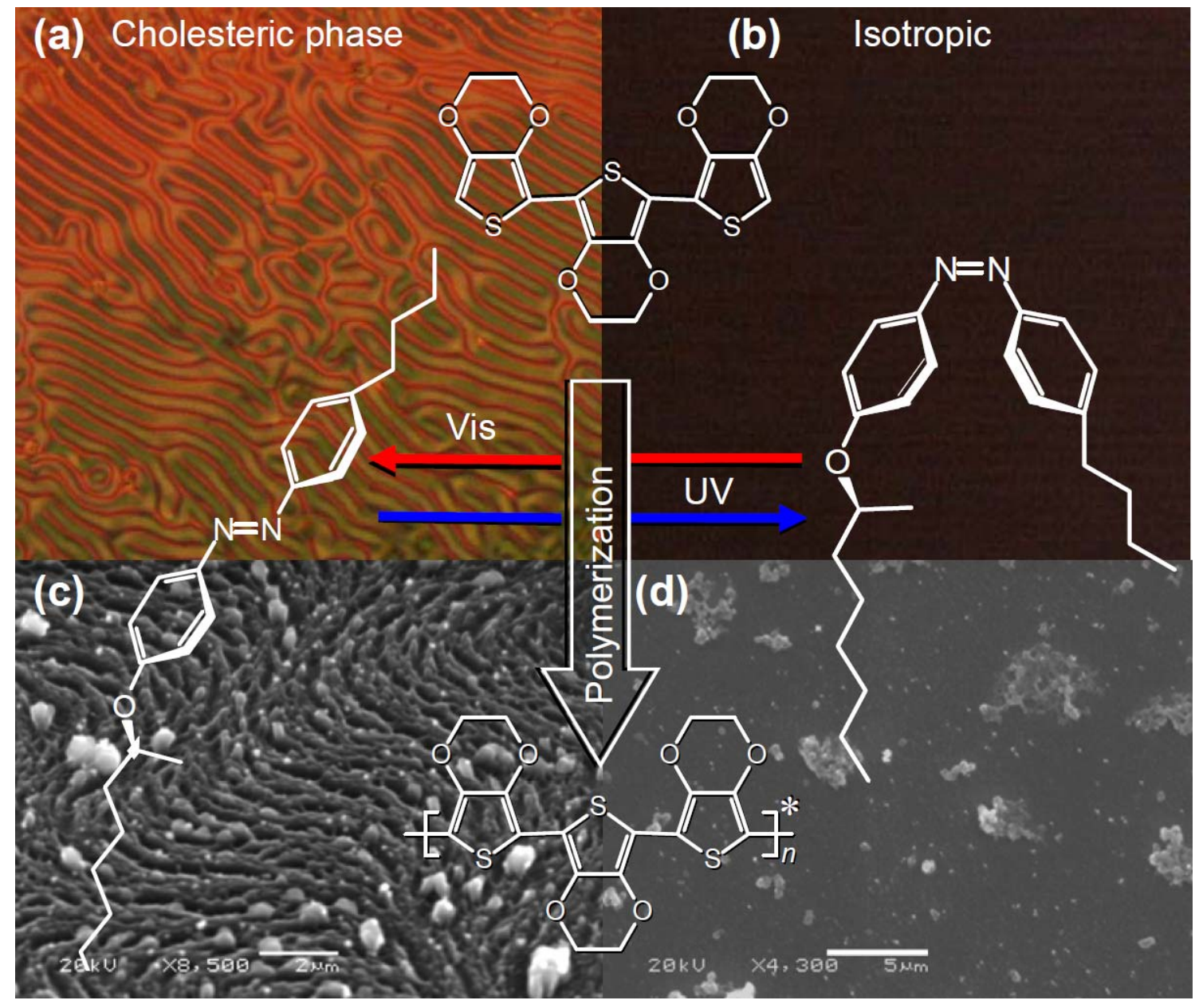

Scheme 3 Light-driven asymmetric polymerization with chiral photo-isomerization dopant. (a) POM image of cholesteric electrolyte solution containing AZO* (Elyte-1, Table 1) under Vis light. (b) Isotropic state produced by incident UV light. (c) SEM image of the polymer prepared in Elyte-1 under Vis light. (d) SEM image of nonordered structure produced by UV light irradiation. 
Goto, H; Kawabata, K

Light driven asymmetric polymerization: an approach for tele-control reaction POLYMER CHEMISTRY (UK), 2(5), 1098-1106 (2011).

Supplementary information for:

\title{
Light driven asymmetric polymerization: an approach for tele-command reaction
}

\author{
Hiromasa Goto*, Kohsuke Kawabata \\ Institute of Materials Science, Graduate School of Pure and Applied Sciences, \\ University of Tsukuba, Tsukuba, Ibaraki, 305-8573 Japan. \\ *Correspondence to H. Goto, e-mail: gotoh@ims.tsukuba.ac.jp
}


Goto, H; Kawabata, K

Light driven asymmetric polymerization: an approach for tele-control reaction POLYMER CHEMISTRY (UK), 2(5), 1098-1106 (2011).

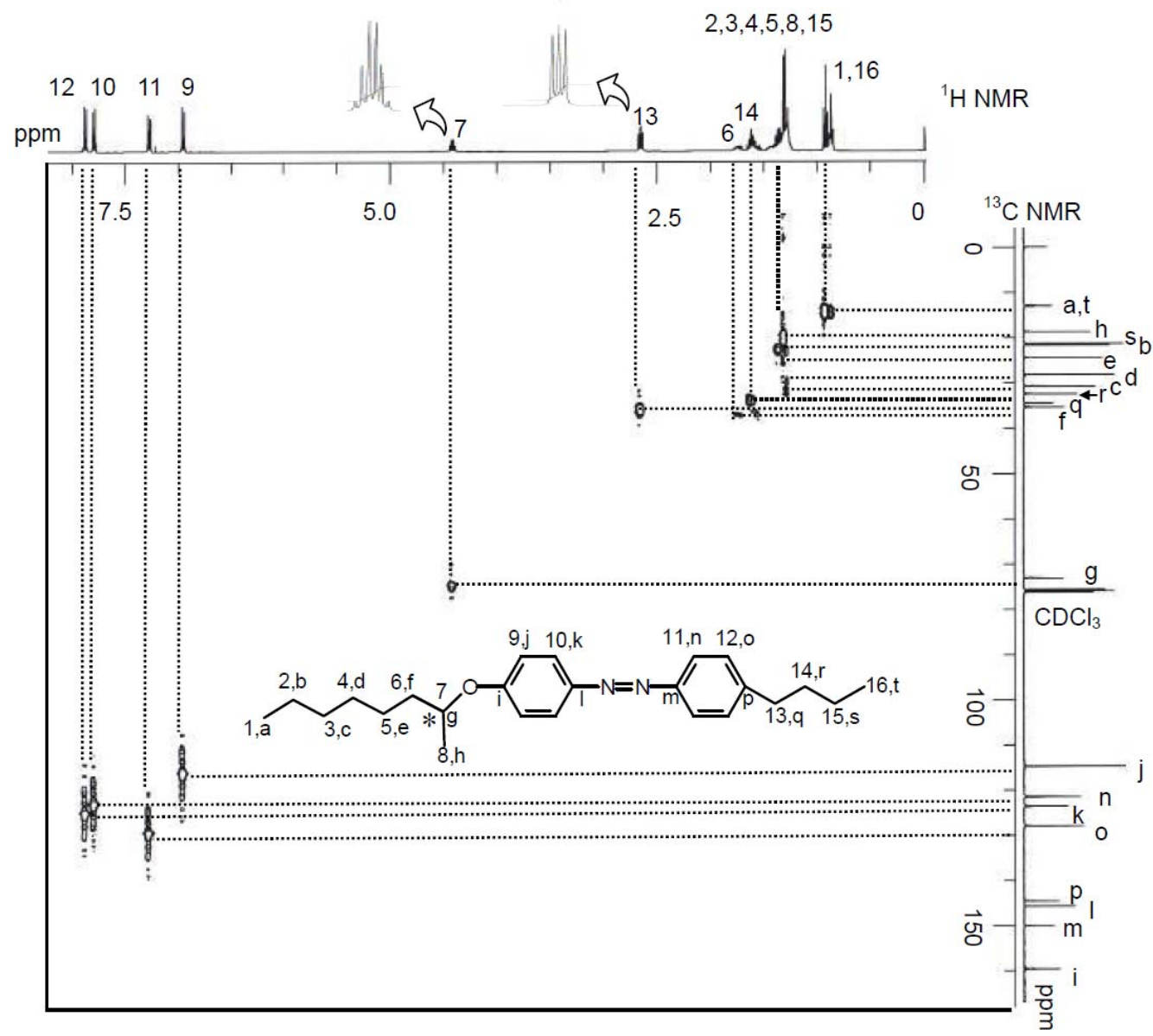

Fig. S1. Heteronuclear Multiple Quantum Coherence (HMQC) $2-\mathrm{D}{ }^{1} \mathrm{H}^{13} \mathrm{C}$ correlation NMR spectrum of AZO*. 
Goto, H; Kawabata, K

Light driven asymmetric polymerization: an approach for tele-control reaction POLYMER CHEMISTRY(UK), 2(5), 1098-1106 (2011).

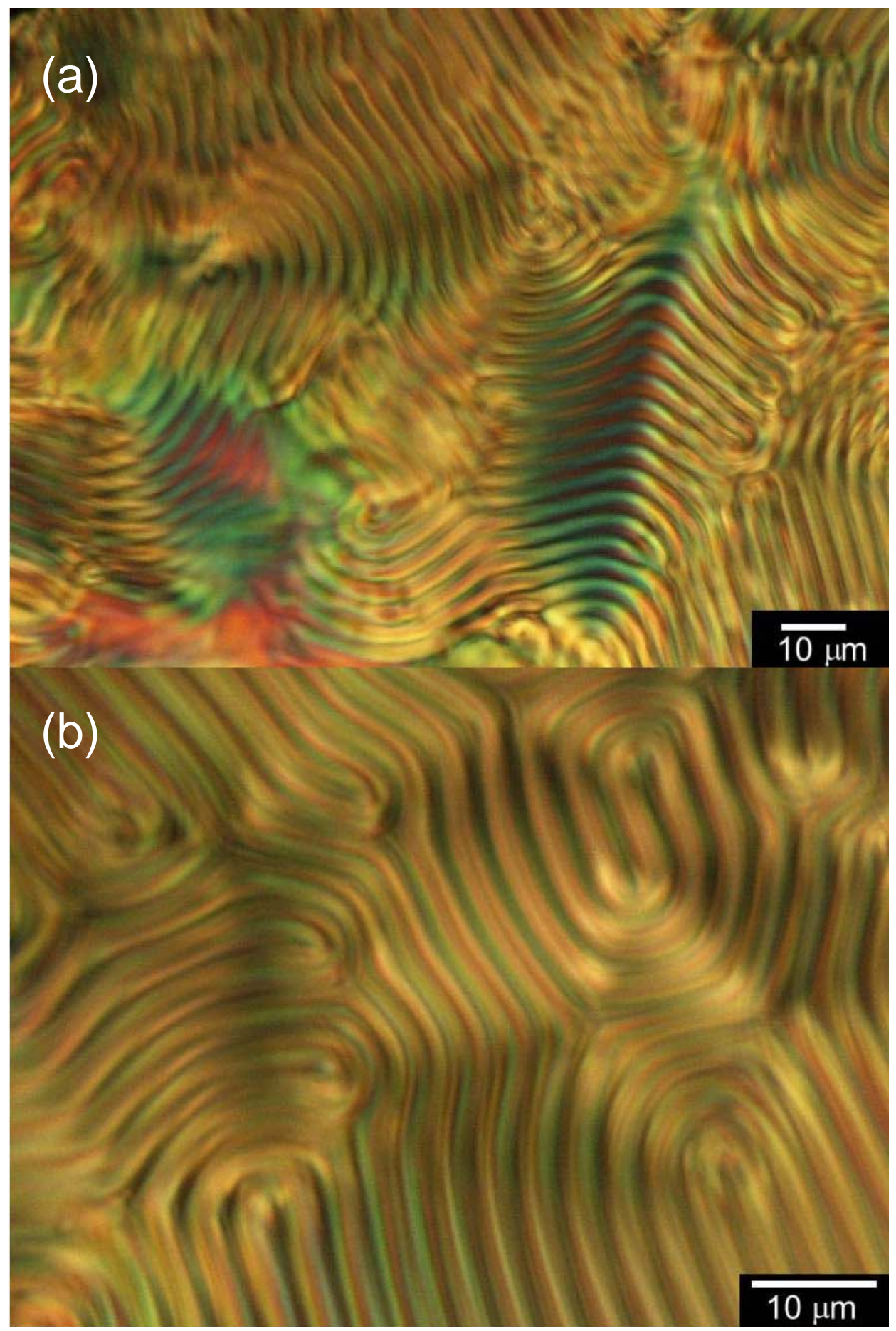

Fig. S2. POM images of monomer-free LC solution containing AZO* $(20 \mathrm{mg})$ in $6 \mathrm{CB}$ $(0.3 \mathrm{~g})$ at $25^{\circ} \mathrm{C}$. (a) $500 \mathrm{x}$, (b) $1000 \mathrm{x}$. 
Goto, H; Kawabata, K

Light driven asymmetric polymerization: an approach for tele-control reaction POLYMER CHEMISTRY(UK), 2(5), 1098-1106 (2011).

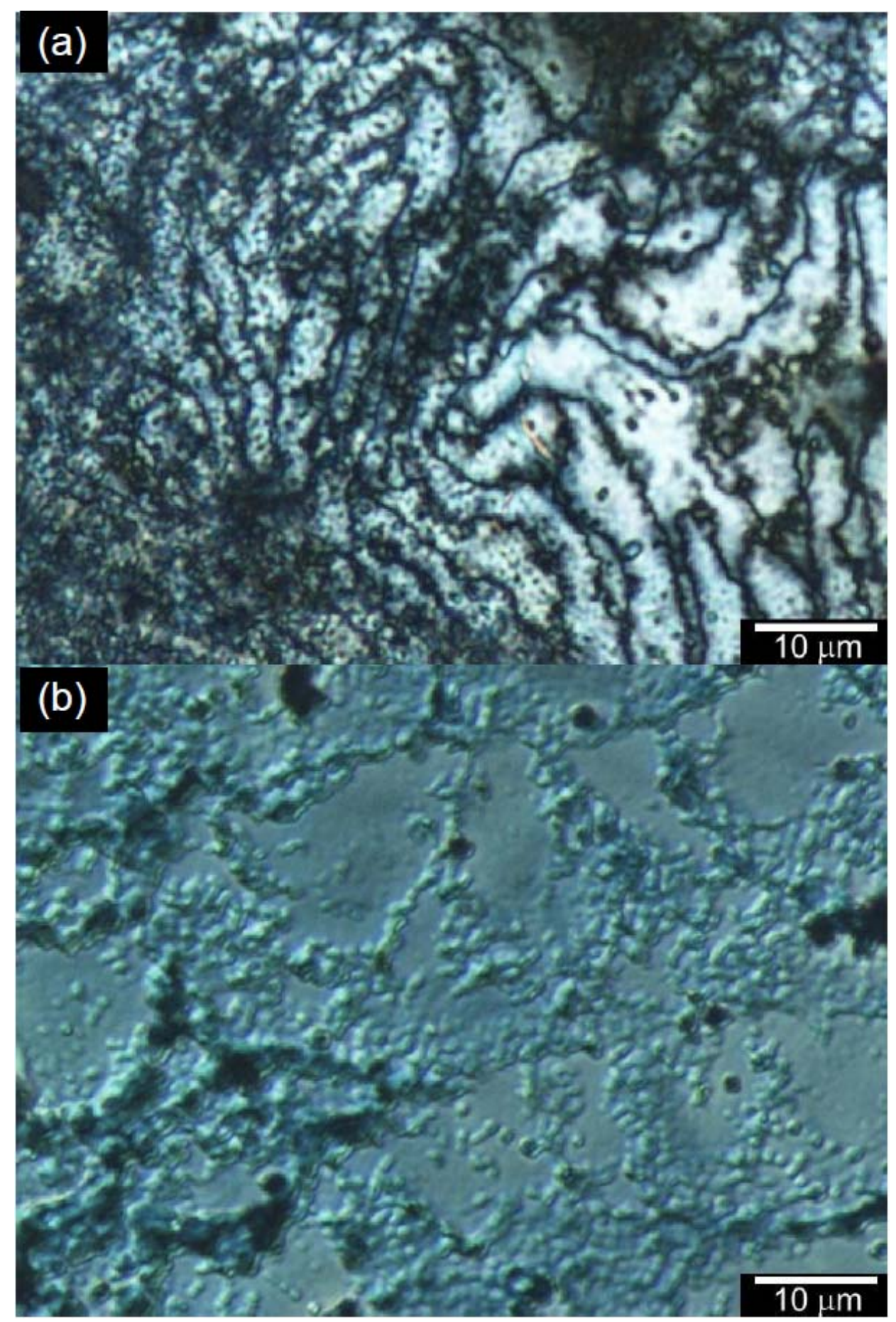

Fig. S3. Differential interference microscopic (DIM) images of PterEDOT prepared under light irradiation. (a) PterEDOT showing Schlieren texture. (b) PterEDOT showing no birefringence. 
Goto, H; Kawabata, K

Light driven asymmetric polymerization: an approach for tele-control reaction POLYMER CHEMISTRY (UK), 2(5), 1098-1106 (2011).

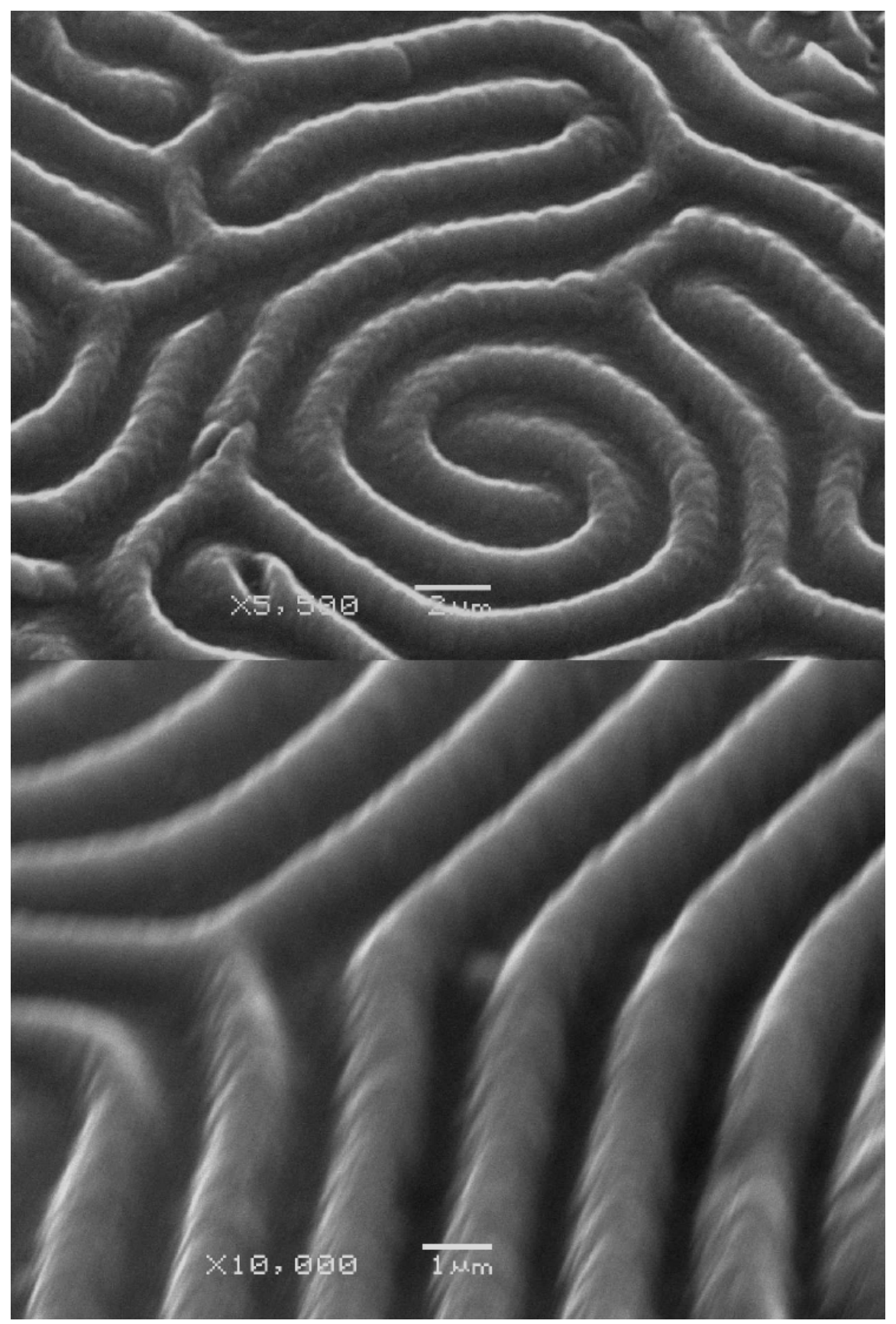

Fig. S4. SEM images of PFFLF prepared under Vis light (PFFLF(Vis)). 
Goto, H; Kawabata, K

Light driven asymmetric polymerization: an approach for tele-control reaction POLYMER CHEMISTRY(UK), 2(5), 1098-1106 (2011).

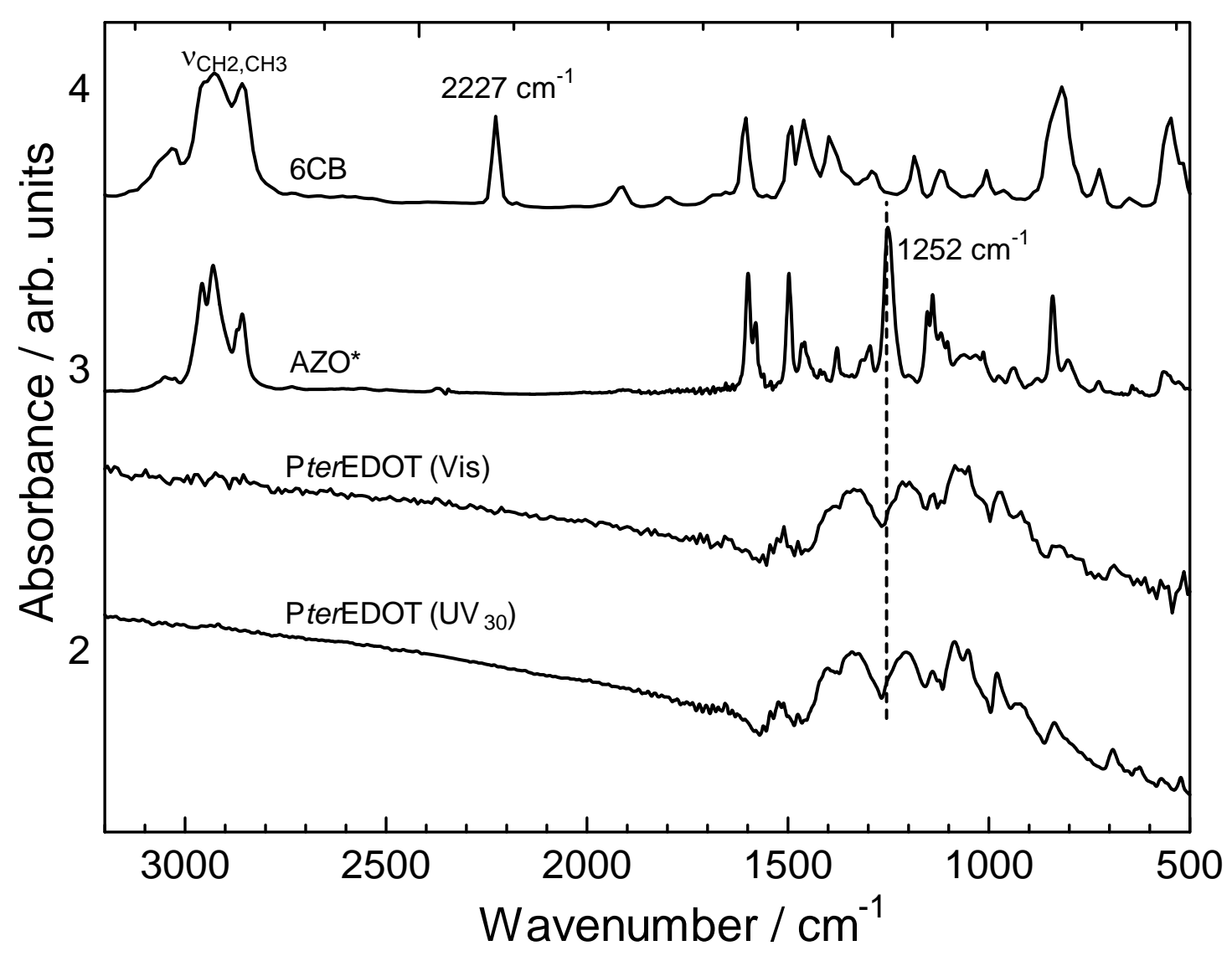

Fig. S5. IR absorption spectra of 6CB, AZO*, PterEDOT(Vis), and PterEDOT(UV $\left.{ }_{30}\right)$. 
Goto, H; Kawabata, K

Light driven asymmetric polymerization: an approach for tele-control reaction POLYMER CHEMISTRY (UK), 2(5), 1098-1106 (2011).

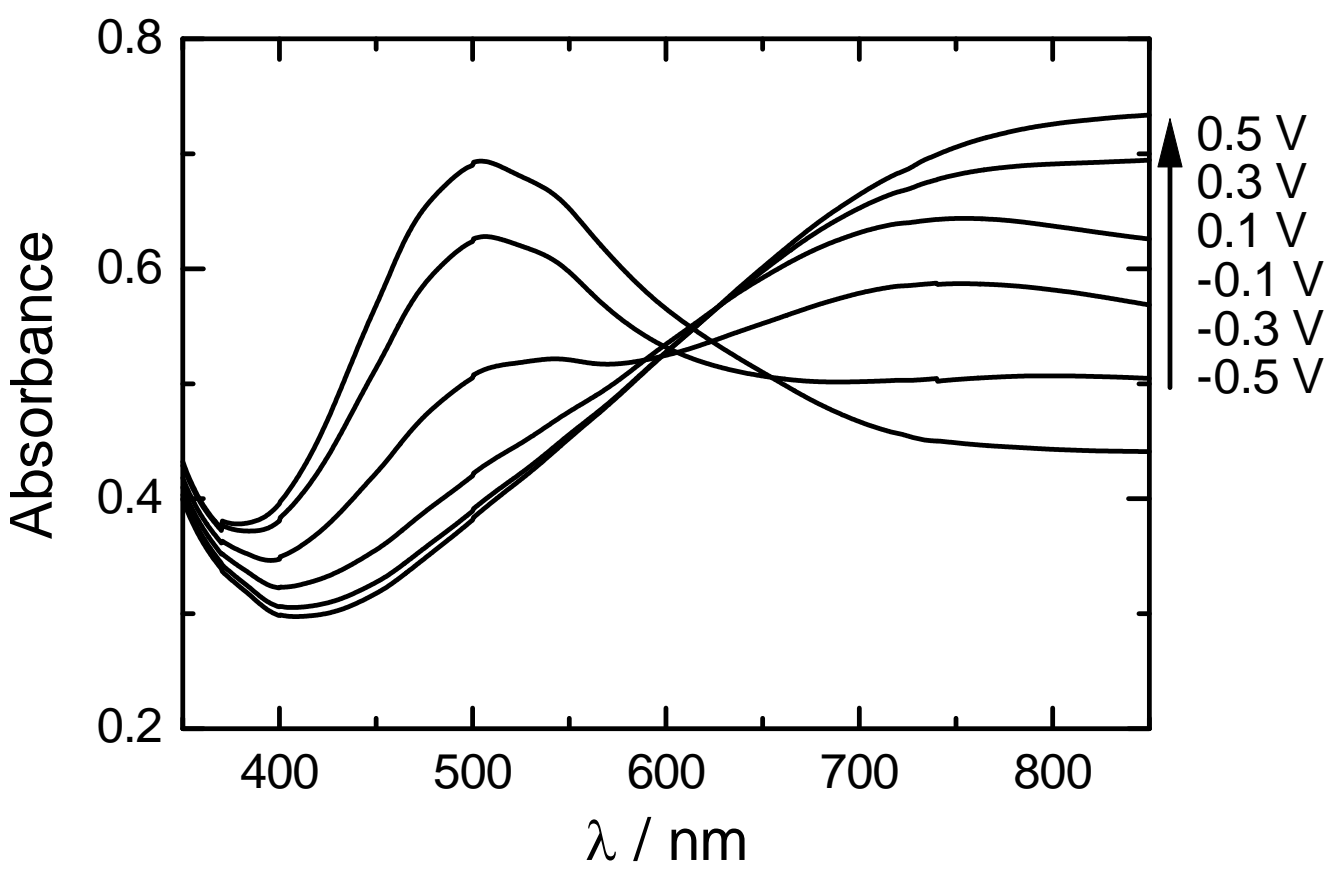

Fig. S6. Optical absorption spectra collected under voltage. Change in absorption of the polymer obtained after UV light irradiation for $30 \mathrm{~min}$ (PterEDOT(UV $\left.\mathrm{UV}_{30}\right)$ ) during the application of voltage. 
Goto, H; Kawabata, K

Light driven asymmetric polymerization: an approach for tele-control reaction POLYMER CHEMISTRY (UK), 2(5), 1098-1106 (2011).

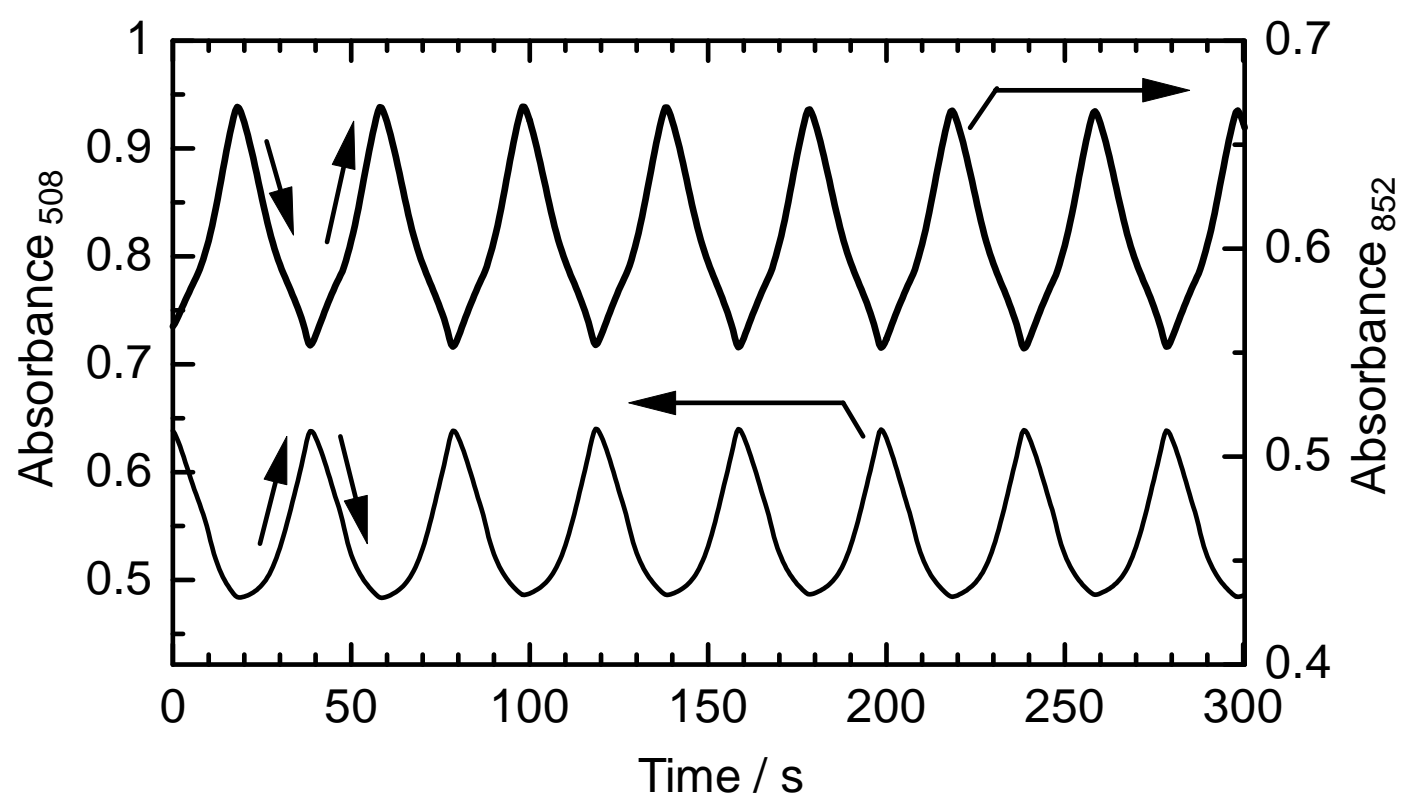

Fig. S7. Reversible changes in absorption for PterEDOT (Vis) (the polymer prepared under Vis light) on ITO glass with repeated scanning between $-0.5 \mathrm{~V}$ and $+0.5 \mathrm{~V}$ vs. $\mathrm{Ag} / \mathrm{Ag}^{+}$as a reference electrode in a monomer-free $0.1 \mathrm{M} \mathrm{TBAP} /$ acetonitrile solution. (Thick line) Absorption at $852 \mathrm{~nm}$. (Thin line) Absorption at $508 \mathrm{~nm}$. 
Goto, H; Kawabata, K

Light driven asymmetric polymerization: an approach for tele-control reaction POLYMER CHEMISTRY (UK), 2(5), 1098-1106 (2011).
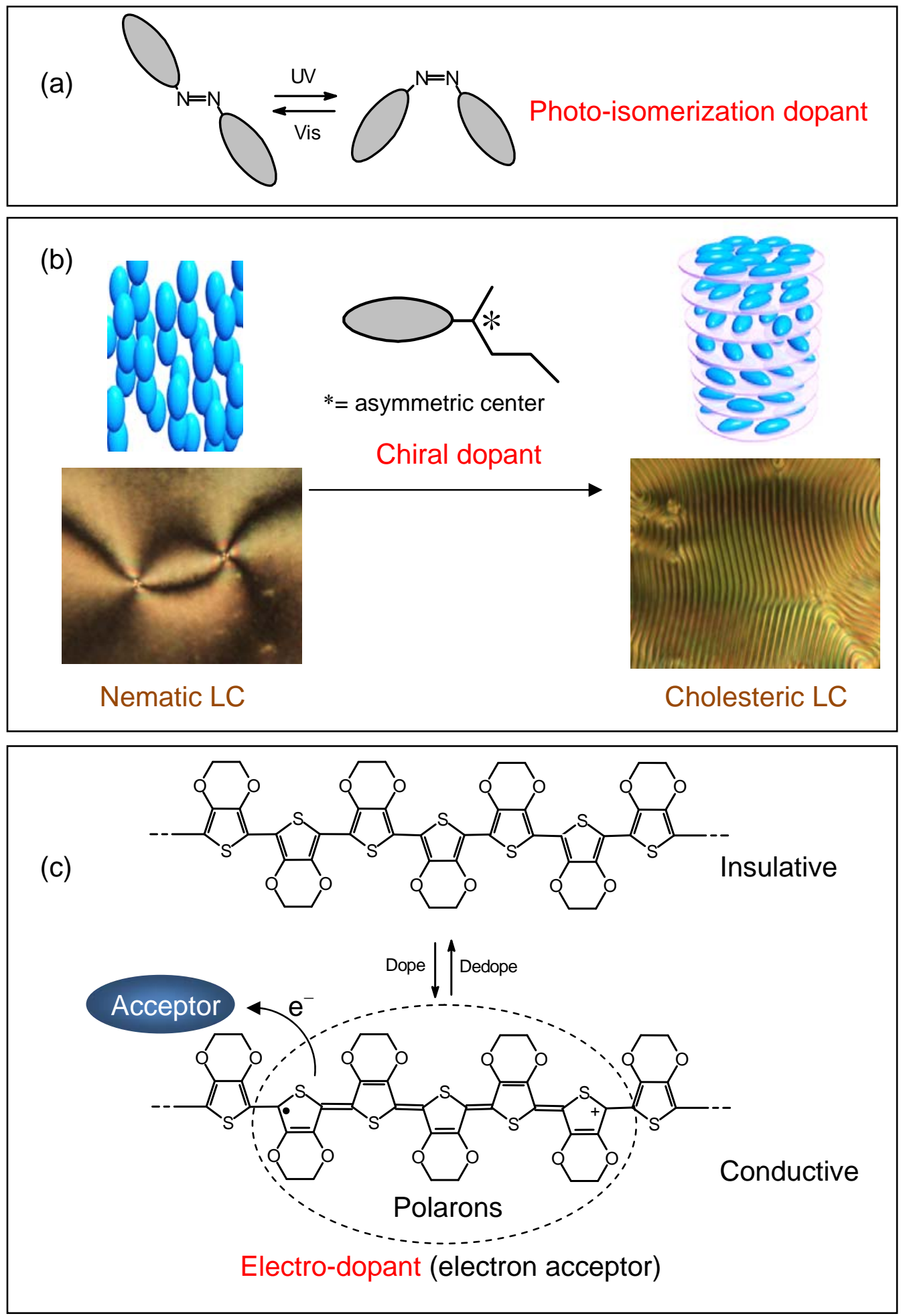

Scheme S1. Three categories of dopants. (a) Photo-isomerization dopant, (b) chiral dopant (although the illustration draws pseudo-layer for convenience, actually cholesteric LC has no pseudo-layer structure), (c) electro-dopant for generation of charged carriers. 